\title{
Mining Indonesian microbial biodiversity for novel natural compounds by a combined genome mining and molecular net- working approach
}

\author{
Ira Handayani 1,2,a, Hamada Saad 3,8,a, Shanti Ratnakomala 2, Puspita Lisdiyanti ${ }^{2}$, Wien Kusharyoto ${ }^{2}$, Janina \\ Krause', Andreas Kulik ${ }^{1}$, Wolfgang Wohlleben ${ }^{1}$, Saefuddin Aziz ${ }^{3}$, Harald Gross ${ }^{3}$, Athina Gavriilidou ${ }^{4}$, Nadine \\ Ziemert 4,5 , and Yvonne Mast $\mathbf{t}^{1,5,6,7, *}$
}

1 Department of Microbiology/Biotechnology, Interfaculty Institute of Microbiology and Infection Medicine, Tübingen (IMIT), Cluster of Excellence 'Controlling Microbes to Fight Infections', University of Tübingen, Auf der Morgenstelle 28, 72076 Tübingen, Germany; e-mail@e-mail.com

2 Research Center for Biotechnology, Indonesian Institute of Sciences (LIPI), Jl. Raya Jakarta-Bogor KM.46, Cibinong, West Java 16911, Indonesia; p2biotek@bioteknologi.lipi.go.id.

3 Department of Pharmaceutical Biology, Institute of Pharmaceutical Sciences, University of Tübingen, Auf der Morgenstelle 8, 72076 Tübingen, Germany; e-mail@e-mail.com

4 Applied Natural Products Genome Mining, Interfaculty Institute of Microbiology and Infection Medicine Tübingen (IMIT), Cluster of Excellence 'Controlling Microbes to Fight Infections', University of Tübingen, Auf der Morgenstelle 28, 72076 Tübingen, Germany.; e-mail@e-mail.com

5 German Center for Infection Research (DZIF), Partner Site Tübingen, Tübingen, Germany

6 Department of Bioresources for Bioeconomy and Health Research, Leibniz Institute DSMZ - German Collection of Microorganisms and Cell Cultures, Inhoffenstraße 7B, 38124 Braunschweig, Germany; e-mail@e$\underline{\text { mail.com }}$

7 Department of Microbiology, Technical University of Braunschweig, Braunschweig, Germany; e-mail@email.com

8 Department of Phytochemistry and Plant Systematics, Division of Pharmaceutical Industries, National Research Centre, Dokki, Cairo (Egypt)

a Ira Handayani and Hamada Saad contributed equally to this work

* Correspondence: yvonne.mast@dsmz.de; Tel.: +49-531-2616-358

\begin{abstract}
(<200):
Indonesia is one of the most biodiverse countries in the world and a promising resource for novel natural compound producers. Actinomycetes produce about two-thirds of all clinically used antibiotics. Thus, exploiting Indonesia's microbial diversity for actinomycetes may lead to the discovery of novel antibiotics. A total of 422 actinomycete strains were isolated from three different unique areas in Indonesia and tested for their antimicrobial activity. Nine potent bioactive strains were prioritized for further drug screening approaches. The nine strains were cultivated in different solid and liquid media and a combination of genome mining analysis and mass spectrometry (MS)-based molecular networking was employed to identify potential novel compounds. By correlating secondary metabolite gene cluster data with MS-based molecular networking results, we identified several gene cluster-encoded biosynthetic products from the nine strains, including naphthyridinomycin, amicetin, echinomycin, tirandamycin, antimycin, and desferrioxamine B. Besides, eight putative ion clusters and numerous gene clusters were detected that could not be associated with any known compound, indicating that the strains can produce novel secondary metabolites. Our results demonstrate that sampling of actinomycetes from unique and biodiversity-rich habitats, such as Indonesia, along with a combination of gene cluster networking and molecular networking approaches, accelerates natural product identification.
\end{abstract}

Keywords: Indonesia, biodiversity, novel antibiotics, drug screening, bioactivity, gene cluster networking, GNPS

\section{Introduction}


It is now 80 years ago that Selman Waksman and Boyd Woodruff discovered actinomycin from Actinomyces (Streptomyces) antibioticus, which was the first antibiotic that has been isolated from an actinomycete [1]. Since then, actinomycetes have been widely used as sources for drug discovery and development [2]. Most antibiotics and other useful natural products applied in human medicine, veterinary, and agriculture are derived from these filamentous bacteria [3,4]. Within the family of Actinomycetales, Streptomyces is the most prominent genus in respect to the production of bioactive secondary metabolites since it is the origin of more than $50 \%$ of all clinically useful antibiotics [5]. Successfully, the intensive screening campaigns of soil-derived streptomycetes yielded many currently recognized drugs, such as the antibacterial substance streptomycin, the antifungal metabolite nystatin, and the anticancer compound doxorubicin during the golden era of antibiotics $[6,7]$. However, in the last few decades, discovering and developing new drugs from these soil microorganisms has declined immensely, while the need for new drugs to overcome multidrug resistance has become greater than ever [8]. Nowadays, one of the major problems in antibiotic screening programs, in particular with streptomycetes, is the high rediscovery rate of already known antibacterial compounds through the classical bioactivityguided paradigms [3].

Sampling actinomycetes from conventional environments such as soils often lead to the rediscovery of known species producing already known antibiotics [9]. Thus, gaining access to unusual unique habitats with the pursuit to isolate new strains as sources of novel bioactive compounds represents a current barrier in drug discovery research [9]. In recent years, the bioprospection of underexplored niches such as extreme or marine environments has become an efficient approach to find novel Streptomyces species that might produce novel compounds $[10,11]$. S. asenjonii strain KNN 42.f isolated from a desert soil sample is one example of a novel Streptomyces species from an extreme habitat, which produces the three new bioactive compounds asenjonamides A-C [12]. Another example is represented by the marine $S$. zhaozhouensis CA-185989 that produces three new bioactive polycyclic tetramic acid macrolactams [13]. Micromonospora sp. as turbinimicin producer represents a further example of prolific marine bacteria that can deliver new antifungal compounds [14]. These are only a few examples demonstrating that abnormal or aquatic territories can be promising avenues as new natural products reservoirs.

Indonesia is the world's largest archipelagic country, spanning into three time zones, covering more than 17,000 islands, with $88,495,000$ hectares of tropical forest, 86,700 square kilometers of coral reefs, and 24,300 square kilometers of mangrove areas [15,16]. It has the second-highest level of terrestrial biodiversity globally after Brazil [17], while ranked as first if marine diversity is taken into account $[16,17]$. With the given species-rich flora and fauna besides endemic and ecologically adapted species, mega biodiversity of microbial species is gratifyingly represented across various unique habitats [18-20], such as acidic hot springs [21], peatland forests [22], the Thousand Islands reef complex [23], Enggano Island [24], fish species [25], and leaves of traditional medicinal plants [26]. Thus, since unique Indonesian niches are expected to deliver untapped potential actinomycetal strains that may produce novel bioactive secondary metabolites, different locations were targeted for the sampling of actinomycetes in this study.

The latest analyses of genome sequence data from actinomycetes revealed a remarkable discrepancy between the genetic potential of the secondary metabolism, known to be encoded by biosynthetic gene clusters (BGCs), and the actual natural compound production capacity of such isolates, upon their growth under standard laboratory conditions. This is attributed to the fact that numerous BGCs are not expressed under conventional lab parameters and occur as so-called "silent" or "cryptic" BGCs [27]. The activation of these silent clusters allows to unlock the chemical diversity of the tested organisms and enables the discovery of new molecules for medical and biotechnological purposes [28]. Thus, several efforts, e.g., involving genetic and cultivation methods, are employed to activate the 
expression of silent gene clusters [29]. One cultivation-based approach to exploit the metabolic capacity of the natural compound producers is the "One strain many Compounds (OSMAC)" strategy [3,28,30]. Such a strategy simply relies on the variation of media compositions as a basis to test for different natural compound production profiles since global changes in the specialized metabolic pathways can occur under variable cultivation conditions [31]. The OSMAC concept represents a well-established model that was suggested nearly two decades ago, however it still leads to the discovery of new chemotypes, such as the novel aromatic polyketide lugdunomycin from Streptomyces sp. QL37 [32] or an eudesmane sesquiterpenoid and a new homolog of the Virginiae Butanolides (VB-E) from from Lentzea violacea strain AS 08 [33]. Along the lines of the OSMAC concept, recently an elicitor screening approach has been suggested, which intends to mimic natural trigger molecules that can induce the biosynthesis of formerly unknown metabolites. This format has been conducted in a high throughput approach and was coupled with MALDI-MS analysis. In the case of $S$. ghanaensis, this strategy led to the discovery of the antibiotically active depsipeptide cinnapetide [34].

Besides the variable trials to elicit the BGCs via pleiotropic approaches, a mass spectrometry dereplication step is frequently inserted in the current screening programs to address the formerly stated challenge of the high rediscovery rate prior to the tedious screening, isolation, and purification processes [35-37]. The utility of such a platform is to pinpoint known compounds in the initial phase of the discovery pipeline and leverage the process of finding new drugs. Integrated genomic and metabolomic mining methods have proven as an efficient dereplication strategy for compound identification in recent years [38-41]. While genome mining involves the identification of putative BGCs based on the genome sequences of the natural compound producers [42,43] using in silico bioinformatics tools such as antiSMASH [44], metabolome mining encompasses sorting out the chemical compounds in extracts of natural compound producers via their mass fragmentation patterns. Counting on the fact that metabolites with a similar chemical architecture tend to generate similar mass fragmentation patterns in mass spectrometry (MS) analysis, the implementation of the computational platform Global Natural Product Social (GNPS) to group the structurally related entities, often derive from a common biosynthetic origin, as a connected set of a molecular family cluster is an overgrowing necessity [45]. Such platform iteratively proves its effectiveness to arrange seamlessly large numbers of samples enabling dereplication and tentative structural identification and/or classification [46]. The combinatorial employment of both computational tools side by side empowers the rapid identification of new substances, which can be highlighted by discovering the antibacterial substance thiomarinol from Pseudoalteromonas luteoviolacea [38] and microviridin 1777, a chymotrypsin inhibitor from M. aeruginosa EAWAG 127a [47].

Taken all together with the promises that highly biodiverse habitats can offer in synergy with an effective and practical mining technique, this study aimed to characterize the secondary metabolomes of selected actinomycetes isolated from three different locations within Indonesia. A collection of 422 actinomycetes from Lombok, Bali and Enggano Islands were sampled and preliminary filtered with different bioactivity tests where nine actinomycetes with the most bioactive potential were nominated for a hybrid genome mining and molecular networking approach in order to assess their biosynthetic capacity for the production of novel natural compounds. 


\section{Results and Discussion}

\subsection{Isolation and Characterization of Indonesian actinomycetes}

To isolate actinomycetes, soil samples were collected from two specific habitats (terrestrial and marine) in three different geographic areas of Indonesia using standard isolation protocols [48-52]. Enggano Island was chosen as a sampling location for terrestrial habitats since it is a pristine island with many endemic species and high biodiversity [53,54], whereas Bali and Lombok Island were selected as sampling sites for marine habitats resulting in 422 strains in total (Figure 1). Among all sampling locations, the Enggano Island soil samples contributed to the highest number of actinomycetes isolates $(56.2 \%)$, followed by sediment samples from Lombok (37.2\%) and Bali island (6.6\%).

In the frame of a preliminary bioactivity screening, all 422 isolates were evaluated for their antimicrobial activities in agar plug diffusion bioassays against selected Gram-positive (Bacillus subtilis, Micrococcus luteus, and Staphylococcus carnosus) and Gram-negative bacteria (Escherichia coli and Pseudomonas fluorescens). The 16 most potent isolates were selected based on their antimicrobial activity against the tested organisms, indicated by the largest inhibition zones around the agar plug. All 16 isolates showed bioactivity against the Gram-positive test organism B. subtilis (Figure 2A) and nine exerted further activity against Gram-negative test strains (Figure 2B), while only four strains (BSE 7-9, BSE 7F, I3, and I6) displayed potency against both (Figure 2).

To investigate the phylogenetic relationship of the 16 bioactive actinomycetal isolates $16 \mathrm{~S}$ rRNA gene sequence analyses were performed. For this purpose, the genomic DNA was isolated from each and was used as template in a PCR approach with 16S rRNA genespecific primers. The resulting $16 \mathrm{~S}$ rRNA gene amplifications were sequenced, and the $16 S$ rRNA gene sequences were compared using the EzTaxon database (www.ezbiocloud.net/) to determine the phylotype of the strains [55]. EzTaxon analysis revealed that all isolates belong to the genus Streptomyces with similarity values amongst the various predicted related species ranging from $98.44 \%$ - $99.89 \%$ (Table 1).

Subsequently, nine strains were prioritized based on their bioactivity profile and taxonomic position. Strains SHP 22-7, BSE 7-9, BSE 7F, I3, I4, I5, and I6 were selected since they showed antibacterial activity against Gram-positive and Gram-negative bacteria (Figure 2A and B). DHE 17-7 and DHE 7-1 were selected as they exerted bioactivity against at least two different Gram-positive test strains. DHE 6-7 and DHE 5-1, which showed bioactivity against all Gram-positive test strains, were not chosen for further analysis because both strains showed a close phylogenetic relationship to Streptomyces parvulus (Table 1), which is a known producer of the polypeptide antibiotic actinomycin D [56]. In an initial attempt with HPLC-MS analysis of the methanolic extracts of culture samples from DHE 6-7 and DHE 5-1, actinomycin D was detected as a product (Figure S1), ruling out both strains from further investigations.

\subsection{Phylogenomic Analysis of Nine Prioritized Indonesian Streptomyces strains}

To obtain a better understanding of the phylogenetic relationship about the prioritized nine Streptomyces strains, a phylogenetic analysis based on their full-length genomes sequences was performed. For this purpose and the genome mining studies mentioned below, the genomic DNA was isolated from each sample and sequenced by using the Pacific Biosciences RS II (PacBioRSII) platform [57-59]. The resultant genome sequences ranged in sizes between 7.05 Mbp (Streptomyces sp. I6) and 8.36 Mbp (DHE 17-7) and GC contents between $72.08 \%$ (DHE 7-1) and 72.47\% (Streptomyces sp. I6) (Table S1), which share comparable values reported for Streptomyces species (genome sizes of 6-12 Mb (genome sizes of 6-12 Mb [60] and GC contents of 72-73\% [61,62]).

In order to run a whole-genome phylogenetic analysis, the genome sequences were submitted to the Type (Strain) Genome Server (TYGS) (https://tygs.dsmz.de) [63], which al- 
lows a phylogenetic analysis based on full-length genome sequences and compares genomic data with the database genomes. The resulting phylogenetic information is more authentic than those obtained from 16S- or multi-locus sequence analysis (MLSA)-based classifications, which only use small sequence fragments as a basis for sequence comparisons [63]. The TYGS analysis provides information on the similarity of a strain to its nearest related type strain, derived from the digital DNA-DNA hybridization (dDDH) values calculated by the Genome-to-Genome Distance Calculator (GGDC) 2.1 (http://ggdc.dsmz.de) [64]. TYGS phylogenomic analysis revealed that all nine isolates belong to the genus Streptomyces. The dDDH values between the nine Indonesian strains and their closest relatives ranged between 31.4\% (Streptomyces sp. I4) and 51.5\% (Streptomyces sp. I6) (using GGDC distance formula 14 ) (Table 2), which is below the threshold of 70\% used for species delineation [65], proposing a novel collection of Streptomyces species.

According to the TYGS phylogenomic tree, the terrestrial Enggano Island strains SHP 227 and DHE 17-7 belong to the same clade (clade A) (Figure 3) and most likely resemble the same type of species with a dDDH value of $86.7 \%$ (Table 2). Both bacteria are found to be closely related to S. luteus TRM 45540, isolated from a soil sample from China [66]. All mangrove isolates originating from sediments of Lombok Island (Streptomyces Sp. I3, I4, and I5) and Bali Island (BSE 7F, and BSE 7-9) were allied in clade B, suggesting a correlative connection (Figure 3). Additionally, the dDDH analysis showed that BSE 7F is closely related to BSE 7-9 with a value of $95.7 \%$ and thus most likely represent the same subspecies (Table 2). While Streptomyces sp. I3 and I4 probably represent the same species having a dDDH score of almost 100\% (Table 2). The nearest related type strain of all five mangrove strains is S. capillispiralis DSM 41695 isolated from a Sweden soil sample [67].

In contrast, the soil DHE 7-1 and mangrove Streptomyces sp. I6, were found to group separately in distinct clades (clade C and D, respectively) (Figure 3). The soil S. bungoensis DSM 41781 collected in Japan [68] shares a dDDH value of $32.3 \%$ as the closest-related strain to DHE 7-1 (Table 2), while the nearest related neighbor of Streptomyces sp. I6 is $S$. spongiicola HNM0071, isolated from a marine sponge collected from China [69] with a dDDH value of 51.5\% (Table 2). Altogether, 16S rRNA gene phylogenetic and phylogenomic studies revealed that all nine prioritized isolates belong to the genus Streptomyces and, based on dDDH analysis, represent novel species (Figure 3).

\subsection{Genetic Potential for Secondary Metabolite Biosynthesis of Nine Indonesian Streptomyces strains}

To infer the genetic potential of the strains for the biosynthesis of secondary metabolites, the genomes were analyzed bioinformatically using the web tool antiSMASH version 5.0 (https://antismash.secondarymetabolites.org) [44]. AntiSMASH analysis yielded a sum of 206 potential BGCs for the nine isolates (Table 3) with the lowest BGC count of 17 for strain Streptomyces sp. I3 and the highest number of 30 BGCs for strain DHE 17-7 (Table 3). On average, this makes 23 BGCs per strain, which is lower than the average value of 40 BGCs reported for Streptomyces genomes [70]. However, the lower BGC count is most likely a result of the underlying PacBio genome sequences, which generally yield less contigs than other sequencing technologies, resulting in less interrupted BGCs and thus less BGC counts in antiSMASH analyses. The genome of DHE 17-7 exhibited a slight correlation between genome size (8,4 Mbp) and the observable number of BGCs (30 BGCs) (Table 3, Table S1). Several of the identified BGCs from the nine Indonesian isolates showed high similarity (>60\%) to already known BGCs (Table 4); e.g. all strains harbored BGCs encoding compounds that are commonly produced by streptomycetes, such as desferrioxamine, which is a vital siderophore for the growth and development [71], hopene, as a substance of the cytoplasmic membrane modulating membrane fluidity and stability [72], and a spore pigment for protection against UV radiation [73]. This result is consistent with previous observations, where these BGCs have been reported for most analyzed Streptomyces genomes [70]. Ectoine and geosmin BGCs were found in all Indonesian isolates except for Streptomyces sp. I6 (Table 4). Besides, albaflavenone BGCs were uncovered in all strains, 
excluding Streptomyces sp. I6 and DHE 7-1. Interestingly, in the genomes of the mangrovederived isolates BSE 7F, BSE 7-9, I3, I4, and I5, two ectoine BGC were identified, suggesting the additional ectoine BGCs may play a role in the adaptation of these organisms to the osmotic stress of such high salinity environments.

Aborycin and alkylresorcinol gene clusters were discovered in the five mangrove Streptomyces strains, whereas amicetin, candicidin, coelichelin, fluostatin M-Q BGCs were only detected for the soil-based isolates SHP 22-7 and DHE 17-7. Candicidin, as an example of a fungizide [74], is most likely produced by the terrestrial streptomycetes in order to defend against local fungal competitors. Coelichelin is a further spotted siderophore which might be necessary for the soil-living streptomycetes to sequester poorly soluble environmental $\mathrm{Fe}^{3+}$ [75], which is quite scarce and highly contested by other microorganisms in soils. The discovery of the same BGC composition in strains derived from the same habitat, such as soil or mangroves, is probably attributed to that each biosynthetic product has its specific biochemical relevance in the respective environment. Of the nine strains, only Streptomyces sp. I6 harbored a staurosporine, scabichelin, echinomycin, flaviolin, and tirandamycin BGC. Likewise, DHE 7-1 together with Streptomyces sp. I6 were the only representatives comprising an isorenieratene BGC among the nine strains (Table 4). Both strains, I6 and DHE 7-1, were found to be phylogenetically distant from the other strains (Figure 3), outlining that phylogenetically related isolates tend to have similar biosynthetic elements known as BGCs shaped by the environmental conditions. A similar finding has already been made by Meij et al., who reported that ecological conditions play an important role in controlling the formation of secondary metabolites in actinomycetes [76].

To glean a more detailed picture about the BGC distribution amongst the strains, the genome sequences from the nine strains have been analyzed using the BiG-SCAPE software (https://bigscape-corason.secondarymetabolites.org/) [77]. BiG-SCAPE allows fast computation and visual exploration of BGC similarities by grouping BGCs into gene cluster families (GCF) based on their sequences and Pfam protein families similarities [78]. Comparing all shared BGCs within the nine Indonesian strains with BiG-SCAPE allows visualization of the more common BGCs (large nodes) and the less frequent ones (doubletons, (singletons are not shown)) (Figure 4). With this approach, we visualized the occurrence of eight GCFs with a similarity of less than $60 \%$ similarity to known BGCs as predicted by antiSMASH. Ectoine-butyrolactone-NRPS-T1PKS GCF, which has similarities with polyoxypeptin (48\%) or aurantimycin A (51\%), was distributed among strains I3, I4, I5 and BSE 7F (Figure 4, Table S6, S7, S9, S10). A type III polyketide (T3PKS) GCF was shared amongst the strains DHE 17-7, SHP 22-7, and DHE 7-1, which showed 7 to $8 \%$ BGC similarity to the herboxidiene BGC (Figure 4, Table S4, S5, S11). In the strains Streptomyces sp. I3 and I4 of clade B, we found the Others-type I polyketide (otherks-T1PKS), which showed 48 to 55\% BGC similarity to nataxazole BGC, and aminoglycoside/aminocyclitol (amglyccycl) BGC type, which led to $2 \%$ similarity to cetoniacytone A BGC (Figure 4, Table S6, S7). We identified two unique GCFs in the BSE 7F and BSE 7-9 strains of clade B, namely transAT-PKS GCF, which showed 54 to $58 \%$ similarity of BGC to the weishanmycin and phenazine BGC types, which did not show any similarity to any BGC in the antiSMASH database (Figure 4, Table S9, S10). Besides, we detected two GCFs of an indole, which showed 23 to $33 \%$ BGC similarity to the 5-isoprenylindole-3-carboxylate $\beta$-D-glycosyl ester BGC and Other BGC type, which do not belong to any BGCs in the antiSMASH database for the phylogenetically related species of SHP 22-7 and DHE 17-7 of clade A (Figure 4, Table S4, S5). Altogether, Big-SCAPE analysis revealed eight unique GCFs, which could not be associated with known BGCs and may have the potential to encode for new substances. Furthermore, the obtained data disclosed that phylogenetically related strains derived from a similar environmental habitat tend to share similar BGC composition profiles. Inferred from this observation, one can conclude that it is worth to make an effort to sample actinomycetes from unique environmental habitats, since this may lead to the isolation of phylogenetically unique species, which have a higher potential to produce novel natural compounds, as also previously described by Hug et al. [9]. 


\subsection{Optimal Cultivation Conditions for Compound Production of Nine Indonesian Streptomyces Strains}

In order to infer the biosynthetic capacity of the prioritized nine isolates in a bioactivity context, various media following the OSMAC strategy were screened to define the optimal production conditions [30,31]. For this purpose, SHP 22-7, DHE 17-7, DHE 7-1, BSE 7-9, BSE 7F, I3, I4, I5, and I6 were each grown in twelve different liquid cultivation media (SGG, YM, OM, R5, MS, TSG, NL19, NL300, NL330, NL500, NL550, and NL800 (Table S2) ) and culture samples were harvested at different time points (48, 72, 96, and $168 \mathrm{~h}$ ). Cell cultures were extracted with ethyl acetate, concentrated in vacuo, and then re-dissolved in methanol. Methanolic extracts were tested in bioassays against a selected panel of pathogenic strains B. subtilis, M. luteus, S. carnosus, E. coli, and P. fluorescens. Samples with the largest inhibition zones in bioassay tests, were defined as the ones grown under optimal cultivation conditions. For each Indonesian Streptomyces strain, the optimal production conditions have been defined for cultivation in liquid (Table S3). In addition, it is hypothesized that filamentous actinomycetes as soil-organisms grow and develop better on solid nutrient substrates and that a well-grown healthy culture produces more diverse secondary metabolites [79]. Thus, to extend the probability of finding new substances by exploring the biosynthetic potential of the nine strains for secondary metabolite production, we recruited an antibiotic extraction also from solid media. For this purpose, each isolate was spread on agar plates consisting of the respective above mentioned media and incubated for seven to ten days at $28^{\circ} \mathrm{C}$ until spores formed. Grown agar samples were squeezed out and concentrated. The aqueous phase of the solid medium extract was used for bioassays and further chemical analysis.

For Streptomyces sp. I3 and I4, the same cultivation parameters were found to be optimal. Both strains showed a promising potency upon their growth in liquid NL550 medium at $72 \mathrm{~h}$ and solid MS medium (Table S3). Such similar production behavior might be ascribed to their most possible likelihood to represent the same species as suggested above. Furthermore, we found that most of the nine isolates (Streptomyces sp. I3, I4, I5, and I6) produced best on solid MS medium (Table S3). In general, MS is a suitable medium for streptomycetes regarding spore isolation [80]. This would support the hypothesis that strains produce better, when they show healthy growth and development.

\subsection{Identification of Natural Compounds from Nine Indonesian Actinomycetes}

To putatively identify the specialized bioactive substances which are produced by the nine isolates under the various conditions, the culture extract samples were submitted to High-Resolution Mass Spectrometry (HRMS) coupled with the GNPS platform. For this purpose, the obtained extracts from the optimal medium in liquid and solid were firstly fractionated by solid-phase extraction (SPE) and then qualitatively profiled against their main crudes and media controls using HPLC. Subsequently, the prioritized profiles and/or SPE fractions that mainly cover the whole metabolomes with fewer media components were chosen for further metabolomics mass identification through HRMS/MS. The acquired MS/MS mass spectra from the positive mode were recruited to build a featurebased molecular network, while the negative ionization was consulted, if needed, during the annotation step to validate more the features identities [45,81]. The dereplication of the known compounds, chemical analogues, and potential novel chemical structures was carried out by either matching their MS/MS spectra against literature if available, GNPS spectral libraries [45] and/or assisted by manual in silico annotation via Sirius+CSI: FingerID 4.0.1 integrated with Antibase and Pubchem databases [82,83] (see material and methods).

Among the numerous identified secondary metabolites from the nine isolates, antimycins cluster were swiftly retrieved through the identical similarity of their MS/MS spectra to the publicly shared ones of GNPS libraries (Figures S2-S4). Tracking down such features in liquid BSE 7F fractions, particularly the one eluted with $100 \% \mathrm{MeOH}$ in negative mode, 
expanded this set with further known members (Figures S5, S6). In alignment with the formerly described positional and stereogenic isomers of the antimycin family entities, the extracted ion chromatograms (EICs) unambiguously displayed such an isomeric behavior under both modes (Figures S2, S4 and S5) [84-86]. In a similar fashion to antimycins, a different cluster comprising ferrioxamines was deciphered with the aid of GNPS spectral libraries. Ferroxamine D1, 655.2758 as $\mathrm{C}_{27} \mathrm{H}_{47} \mathrm{FeN}_{6} \mathrm{O}_{9}$ [87,88], was displayed as the primary ion linked with an additional unknown analogue, 626.3205 as $\mathrm{C}_{26} \mathrm{H}_{50} \mathrm{FeN}_{8} \mathrm{O}_{6}$ (Figure S7). Despite the fact of observing these two features under only solid cultivations parameters across different isolates (Streptomyces sp. I3, I4, I6, BSE 7F, DHE 17-7, and SHP 22-7) with variable concentrations (Figures S8, S9), two extra unknown amphiphilic trihydroxamate-containing siderophores were also grouped (Figures S7 and S10). Interestingly, BSE 7-9 was the sole producer of such amphiphilic entities under exclusive liquid conditions. Moreover, two additional unknown ferrioxamines were retrieved as unique features singly produced by the DHE 17-7 isolate (Figure S11).

Analogously, staurosporine, with two further congeners, was dereplicated from the I6 samples assisted by shared spectral repositories (Figure S12). Manual annotation of a pair of singletons, 1137.45 as $[\mathrm{M}+\mathrm{H}]^{+}$and 560.22 as $[\mathrm{M}+2 \mathrm{H}]^{2+}$ from the I6 extract, uniquely grown under solid conditions, could decipher echinoserine and depsiechinoserine, respectively (Figures S13-S14) [89,90]. Although the two features were supposed to group together considering their skeletons, the MS/MS spectra of their triggered singly and doubly pseudo molecular ions were different enough not to serve such a purpose resulting in scattered self-looped nodes (Figures S13-S14). Furthermore, traces of the structurally related echinomycin [91] were also observed within Streptomyces sp. I6 extracts, expanding in this way the molecular compound family (Figure S15). Likewise, a tirandamycins cluster was disclosed in Streptomyces sp. I6 extracts upon liquid cultivation depicting the known tirandamycin A in connectivity with further related chemotypes (Figure S16). In parallel, the observed UV absorbance of the annotated mass ion at $\mathrm{m} / \mathrm{z} 418.18$ as tirandamycin A was in alignment with its reported characteristic value [92,93], additionally confirming the identity of the dereplicated feature (Figure S17). Notably, the anticipated molecular formula of the grouped ions of the tirandamycin cluster, besides their degrees of unsaturation, were also reflected by their observed UV absorbances, which differed from the characteristic known one (Figure S17).

An additional constellation of ions mainly derived from isolates BSE 7-9 and I5 was uncovered through manual annotation as naphthyridinomycins cluster (Figure S18). The in silico annotation considering the molecular formula prediction and their $\mathrm{MS}^{2}$ spectra deconvoluted naphthyridinomycin-A, aclidinomycin A, and bioxalomycin- $\beta 2$ besides several unknown related products (Figures S19-S22) [94-96]. Similarly, the manual interrogation of an exclusive group of ions derived from DHE 17-7 led to the putative dereplication of ECO-501, a PKS product so far only reported from Amycolatopsis orientalis ATCC 43491 [97] (Figure S23). Interestingly, the putative annotation of such a feature was in complete alignment regarding the observed UV absorbance and the formerly reported MS/MS spectra (Figures S24-S25). Moreover, amicetin and cytosaminomycins as structurally-related entities were uncovered from SHP 22-7 samples as a big group of ions (Figures S27-S29), encompassing a wide scope of structural modifications as expected according to previous reports in addition to a putatively new set of congeners (Figures S27 and S30) [98-100].

The compound naphthyridinomycin was detected in several culture extract samples from strains of mangrove origin, such as Streptomyces sp. I3, I4, I5, BSE 7F, and BSE 7-9 (Figure 5, Table 5), while amicetin was detected as a biosynthetic product from the isolates SHP 22-7 and DHE 17-7 obtained from soil samples of Enggano Island (Figure 5, Table 5). Furthermore, we observed that Streptomyces sp. I6 produces echinomycin (Figure 5, Table 5), a substance also reported as the biosynthetic product from the closely related type strain Streptomyces spongiicola HNM0071, which was originally derived from a marine sponge [101].These results underline our assumption that phylogenetically related strains are likely to produce similar compounds as a response to their natural habitat environmental 
conditions. Specifically, the isolates Streptomyces sp. I3 and I4 have been found to most likely represent the same species derived from a similar habitat as indicated by the dDDH value of almost $100 \%$ and the high overall similarities of BGC composition and secondary metabolite production profile of both strains (see above). In this context, it should be mentioned that current antibiotic research often address the problem of dereplication of known compounds during drug screening approaches [102-104]. however, what should also be taken into account is the fact that there is also an issue of dereplication of producer strains as observed in the current study. Thus, it is worth to put effort into phylogenetic profiling at the beginning of the screening strategy in order to sort out known producer strains.

Interestingly, the desferrioxamine molecular family was only detected for samples of strains grown on solid media (Table 5 and Table 6). In addition to the above-mentioned metabolites, the solid media uniquely delivered a putative new molecular family consisting of likely three peptides with $m / z 598.2834[\mathrm{M}+2 \mathrm{H}]^{2+}, 662.8048[\mathrm{M}+2 \mathrm{H}]^{2+}$ and 727.3259 $[\mathrm{M}+2 \mathrm{H}]^{2+}$ for which no known substance could be associated. These compounds were detected in samples of strains I3, I5 and BSE 7F (Figure S31, Table 6), highlighting that cultivation conditions have a substantial effect on the chemical profiles. A further example of rendering the impact of the adopted cultivation method was represented with an additional cluster of unknown features from SHP 22-7 isolate, which were exclusively produced under non-liquid fermentation (Figure S32).

Within the same context, strain DHE 17-7 also offered several groups of putative new compounds detected when grown in a liquid medium exemplified by the observed set of the doubly charged entities (Figure S33) (Table 6). Thus, in regard to drug discovery efforts strain DHE17-7 is the most promising strain to be investigated further. The potent biosynthetic capacity is also reflected by the genetically encoded biosynthetic potential since DHE17-7 has a total of 30 BGCs, which is the largest BGC set compared to the other Indonesian strains (Table 3). In summary, eight potential novel compounds have been identified as biosynthetic products from the Indonesian strains, which could not be associated to any known compound and thus demonstrates the value of new strains for drug discovery research.

Furthermore, we observed a correlation between growth conditions and compound production. It is known that sources of complex nitrogen such as soybean meal and corn steep liquor can increase desferrioxamine production in streptomycete [105,106]. Interestingly, desferrioxamine B/D and its analogs has been mainly identified for strains grown on solid media, such as MS agar (Streptomyces sp. I3, I4, I6) and NL300 agar (SHP 22-7) (Table 5 and Table S3), which contain soy flour and cotton seed powder, respectively (Table S2). We could detect desferrioxamine only in samples obtained from strains grown on solid medium. This might be because in liquid media iron $\left(\mathrm{Fe}^{3+}\right)$ is more evenly distributed compared to solid media. Thus, cells grown on solid media might be faced with local iron depletion conditions, which lead to induction of desferrioxamine biosynthesis [75]. In addition to desferrioxamine and its analogs, several known and unknown compounds were only discovered in samples from strains grown on solid medium, i.e., the two known compound echinomycin and tirandamycin for Streptomyces sp. I6, and two putative compounds for Streptomyces sp. I3; I4; I5; BSE 7F with $m / z 1194.554[\mathrm{M}+2 \mathrm{H}]^{2+}$ and $\mathrm{m} / \mathrm{z} 1323.595$ $[\mathrm{M}+2 \mathrm{H}]^{2+}$ (Table 5 and Table 6). Apart from that, we also found some unknown and known compounds in strains grown in liquid media only, such as amicetin (SHP 22-7 and DHE 17-7), antimycin and its analogs (BSE 7F), ECO-0501 (DHE 17-7), MY336-a (BSE 7-9), or several putative compounds for strains Streptomyces sp. I6 and DHE 17-7 (Table 5 and Table 6). This indicates that cultivation conditions significantly affect the formation of substances. Therefore both, the liquid and solid cultivation approach are feasible for increasing the probability of discovering new compounds.

2.6. Identification of potential BGCs Responsible for Compound Production in the Nine Indonesian Streptomyces strains 
To identify the BGCs responsible for compound production in the nine Indonesian Streptomyces strains, we aimed to link the compound production profile and BGC composition by correlating the BGCs data with the MS-based molecular networking results. As described above, strains SHP 22-7, I3, I4, and I6 produce desferrioxamine B/D when grown on solid media (Table 5). We observed that the corresponding BGCs associated with desferrioxamine B/D bio-synthesis were present in all of the four strains. Furthermore, we were able to assign the BGC responsible for the biosynthesis of naphthyridinomycin in the strains BSE 7F, BSE 7-9, I3, I4, and I5 (Table 5). Additional BGCs could be assigned to the compound formations of amicetin in SHP 22-7 and DHE 17-7, antimycin in BSE 7F, echinomycin, staurosporine and tirandamycin A in I6 (Table 5). The BGC encoding the biosynthesis of the compound MY336-a in BSE 7-9 could not be clearly identified. MY336a was originally identified as a product from Streptomyces gabonae, but so far no corresponding BGC has been described to encode the biosynthesis of this substance [107]. Since the compound is relatively small and the biosynthetic origin is unclear, it is rather unreliable to assign specific gene sequences as a potential coding region for this substance. Furthermore, we could not identify the BGC encoding the biosynthesis of ECO-0501 in strain DHE 17-7 based on the antiSMASH output. A potential candidate gene cluster could be cluster region 24, which is a predicted type I PKS BGC that shows some similarity $(<55 \%)$ to BGCs encoding structurally related macrolactam natural products, such as vicenistatin, sceliphrolactam and streptovaricin (Figure S34).

In addition to the metabolites mentioned earlier, we also discovered two putative compounds with $\mathrm{m} / \mathrm{z} 1194.554[\mathrm{M}+2 \mathrm{H}]^{2+}$ and $\mathrm{m} / \mathrm{z} 1323.595[\mathrm{M}+2 \mathrm{H}]^{2+}$ for which no known substances could be associated. These compounds were detected in samples of strains Streptomyces sp. I3, I5, I4 and BSE 7F grown on solid media (Table 6). Since the compounds have a quite high molecular mass, it can be estimated that the encoding BGC is rather large and shared amongst the four strains. For all four strains an "Ectoine-ButyrolactoneNrps-Other-T1pksA" BGC could be detected (Figure 4), which shows a $48 \%$ similarity to a polyoxypeptin BGC. The BGC is located on region 15 in strain Streptomyces sp. I3, on region 15 in strain Streptomyces sp. I4, on region 16 in strain Streptomyces sp. I5, and region 16 in strain BSE 7F. (Table S6, 7, 8, 9). A similar cluster was found on region 21 and 22 for the phylogenetically related strain BSE 7-9, for which, however, no respective compound was detected (Table S10). Besides, we found several putative compounds with the masses $\mathrm{m} / \mathrm{z} 442.287[\mathrm{M}+2 \mathrm{H}]^{+}, \mathrm{m} / \mathrm{z} 449.294[\mathrm{M}+2 \mathrm{H}]^{+}, \mathrm{m} / \mathrm{z} 638.508\left[\mathrm{M}-\mathrm{H}+\mathrm{HCO}_{2} \mathrm{H}\right]^{-}$, and $\mathrm{m} / \mathrm{z} 955.566$ $\left[\mathrm{M}-\mathrm{H}+\mathrm{HCO}_{2} \mathrm{H}\right]$ - for strain DHE 17-7 when grown in liquid medium, which were not associated to known substances (Table 6). Five BGCs are present in DHE 17-7 (region 10, 16, 17,22 , and 28), which do not show any similarity to known BGCs in the antiSMASH database and nine BGCs (region 3, 4, 6, 11, 13, 19, 24, 25, and 26) have similarities of less than $50 \%$. Thus, the so far unknown metabolites might be encoded by some of the unique BGCs from DHE 17-7 (Table S4).

Altogether, the combined GNPS and cluster networking approach disclosed several potentially novel compounds from the Indonesian strains Streptomyces sp. I3, I4, I5, I6, BSE 7F, BSE 7-9, and DHE 17-7, some of which could be assigned to potential encoding BGCs and some are expected to be encoded by unique BGCs. The new Indonesian isolates thus represent a valuable resource for further drug research and development approaches. We conclude that the combined phylogenomic, GNPS and cluster networking approach is an efficient strategy to prioritize phylogenetically unique producer strains and focus on potentially novel compounds encoded by special BGCs

\subsection{Figures, Tables and Schemes}




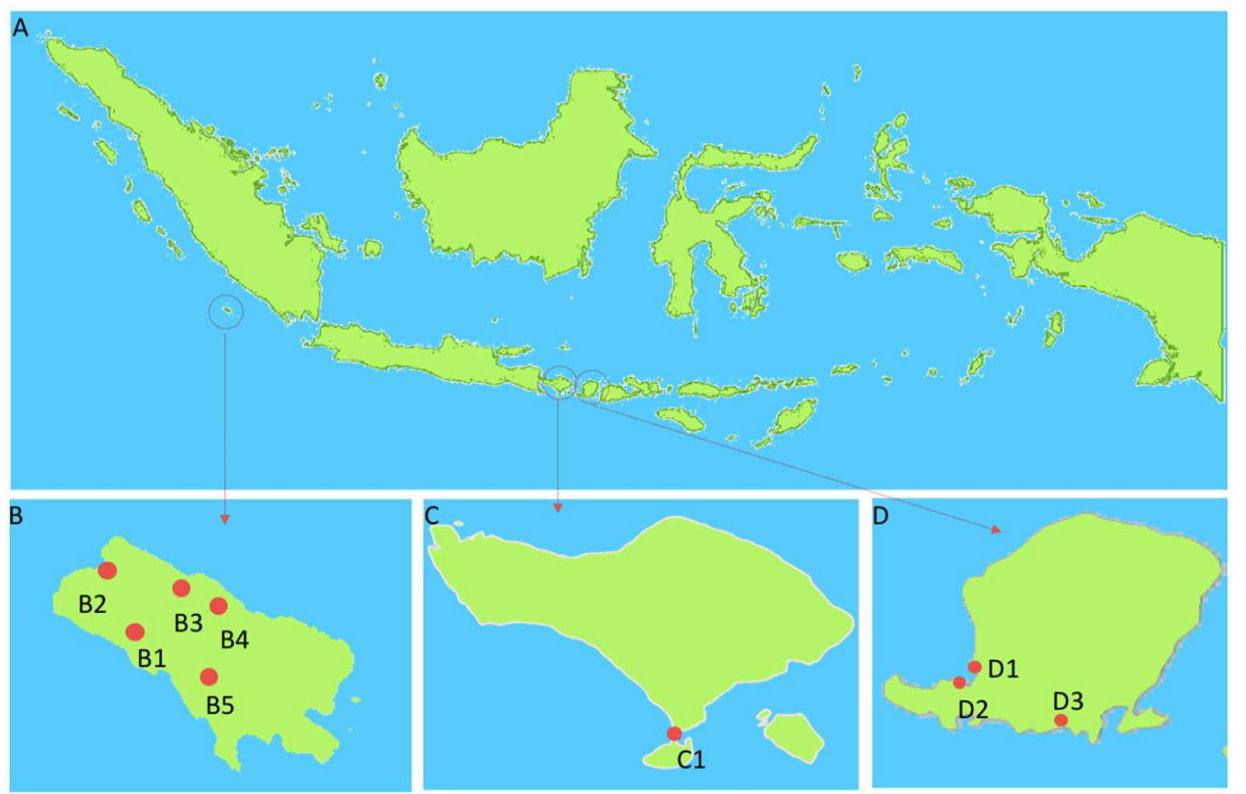

Figure 1. Map of Indonesia showing three geographical regions (A). Sampling site location in Enggano Island (B), Bali Island (C), Lombok Island (D). Red dot shows the sampling locations at Enggano Island, B1: Desa Meok; B2: Desa Banjar Sari; B3: Bak Blau Waterspring, Desa Meok; B4: Desa Boboyo; B5: Desa Malakoni; at Bali Island C1 for Kuta; and Lombok Island D1: Pantai Cemara, Lembar; D2: Pantai Tanjung Kelor, Sekotong; D3: Pantai Koeta.

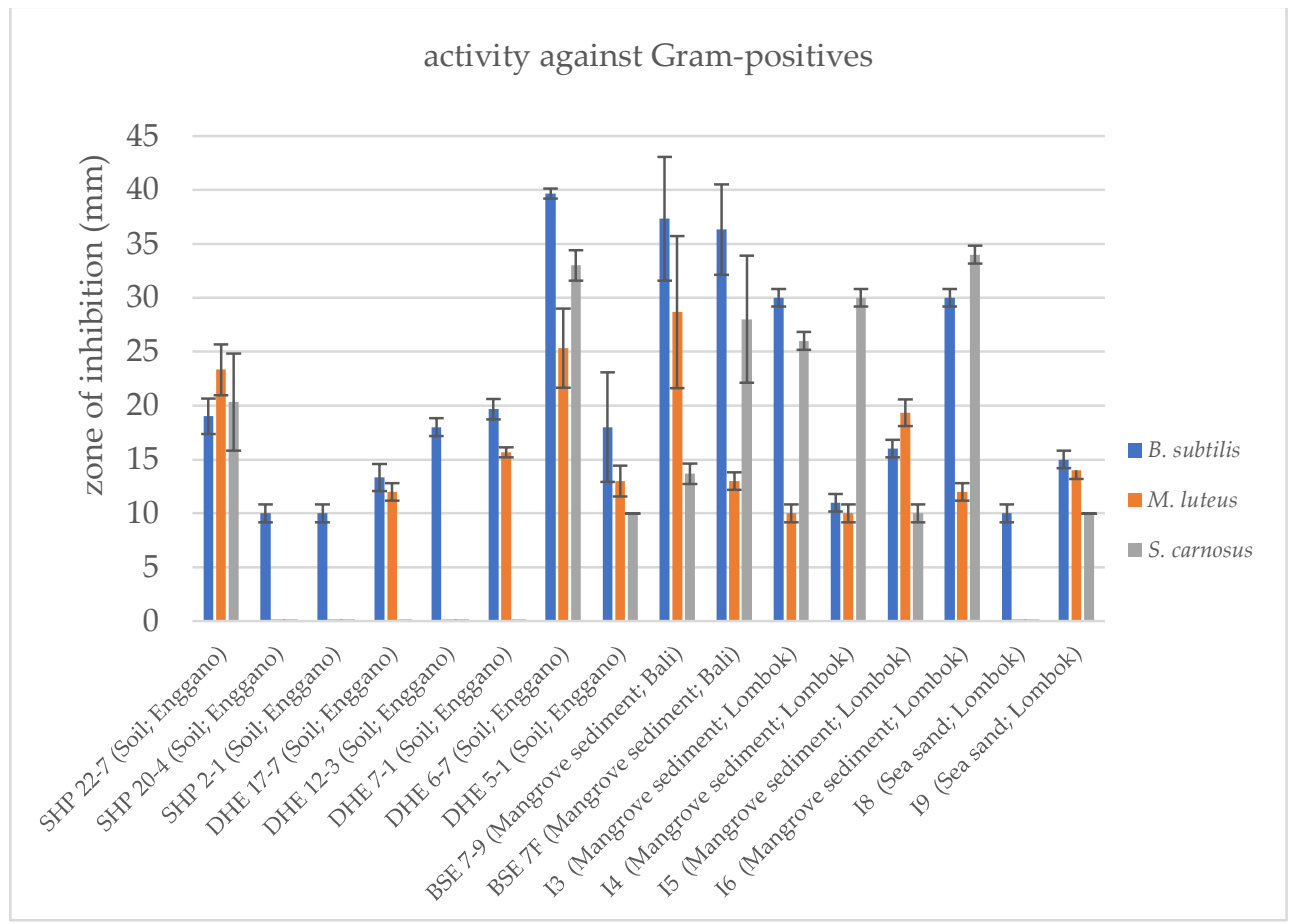

(A) 


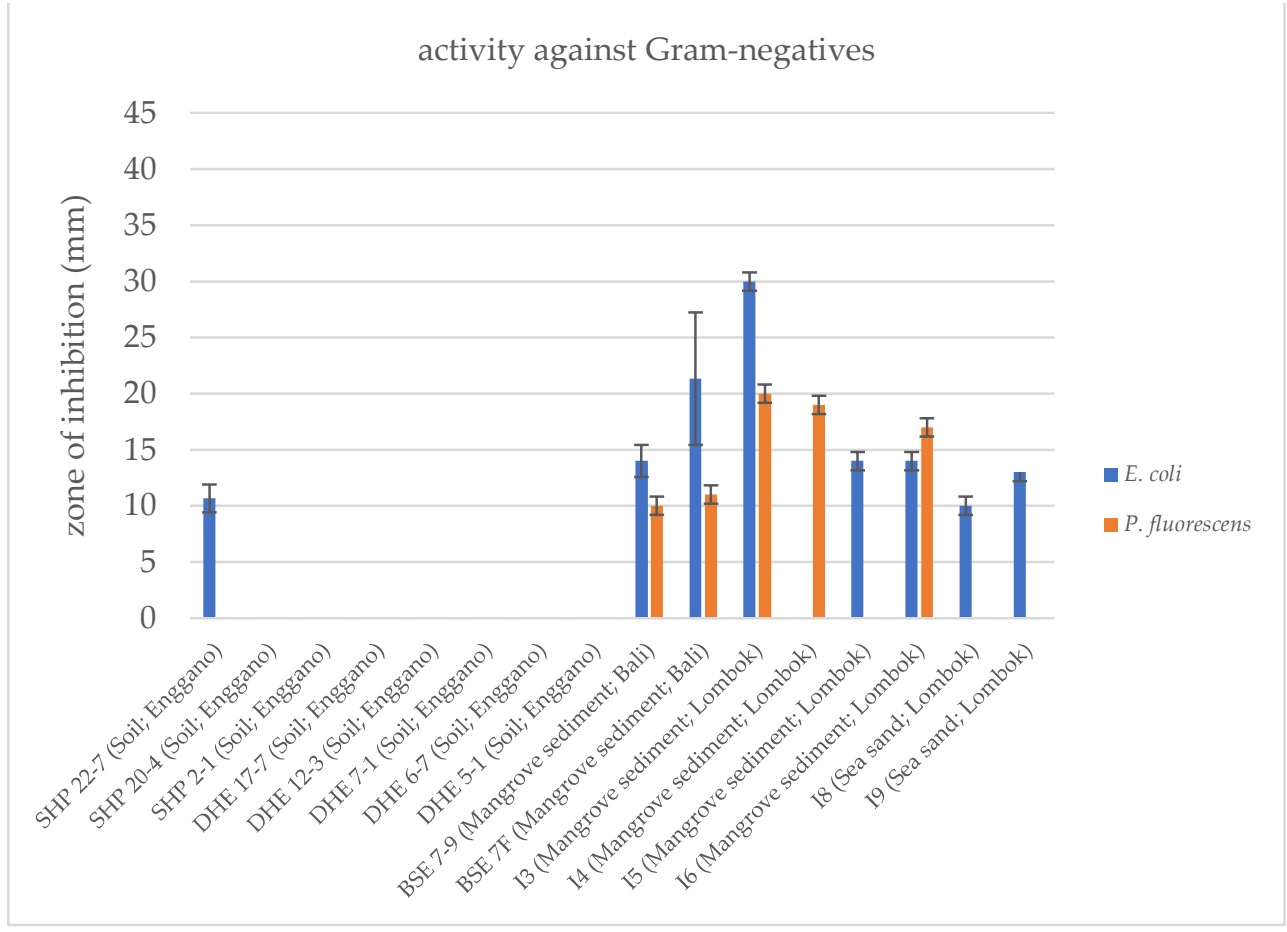

(B)

Figure 2. Antimicrobial bioassays with 16 Indonesian actinomycetes strain samples against Gram-positive (A) and Gram-negative test strains (B). Inhibition zone diameters of agar plug test assays are given in $\mathrm{mm}$. Data shown are as the result of three independent biological replicates.

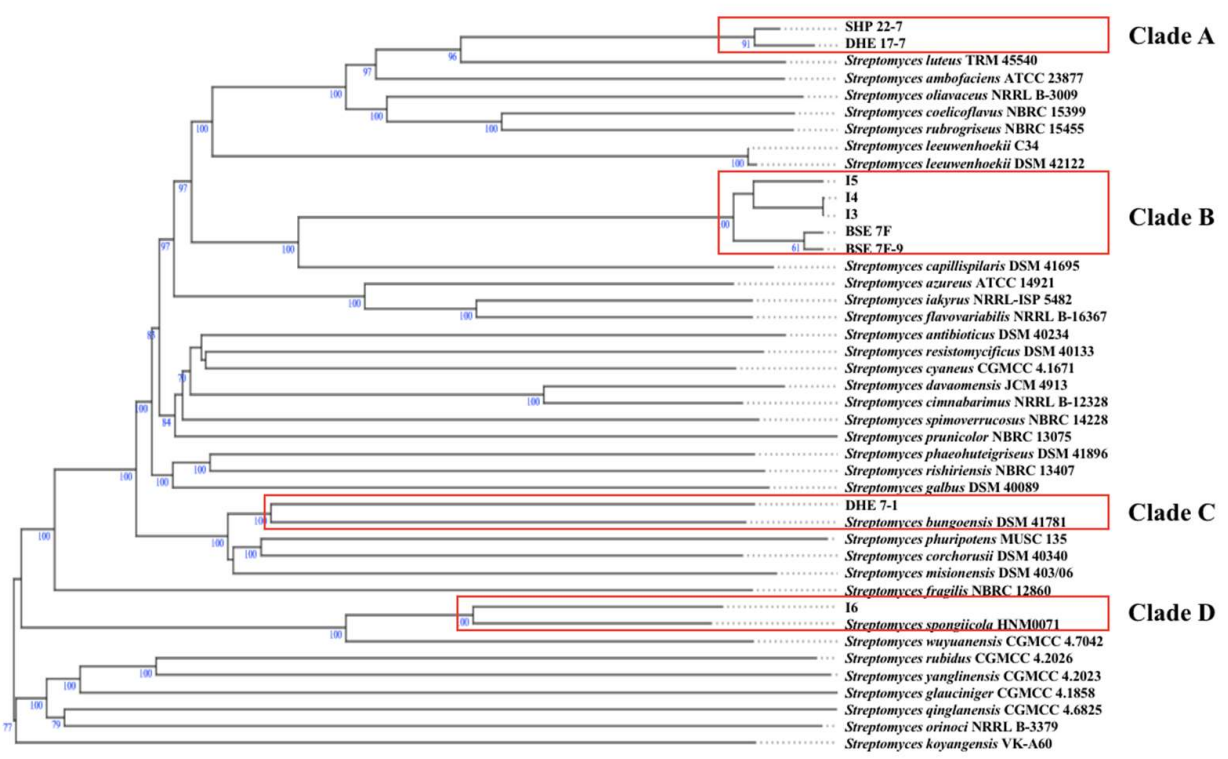

Figure 3. Whole-genome sequence tree generated with the TYGS web server for nine Indonesian Streptomyces isolates (highlighted by red boxes) and closely related type strains. Tree inferred with FastME from GBDP distances was determined from genome sequences. The branch lengths are scaled in terms of GBDP distance formula $d_{5}$. The numbers above branches indicate GBDP pseudo-bootstrap support values $>60 \%$ from 100 replications, with an average branch support of $84.4 \%$. The tree was rooted at the midpoint. 


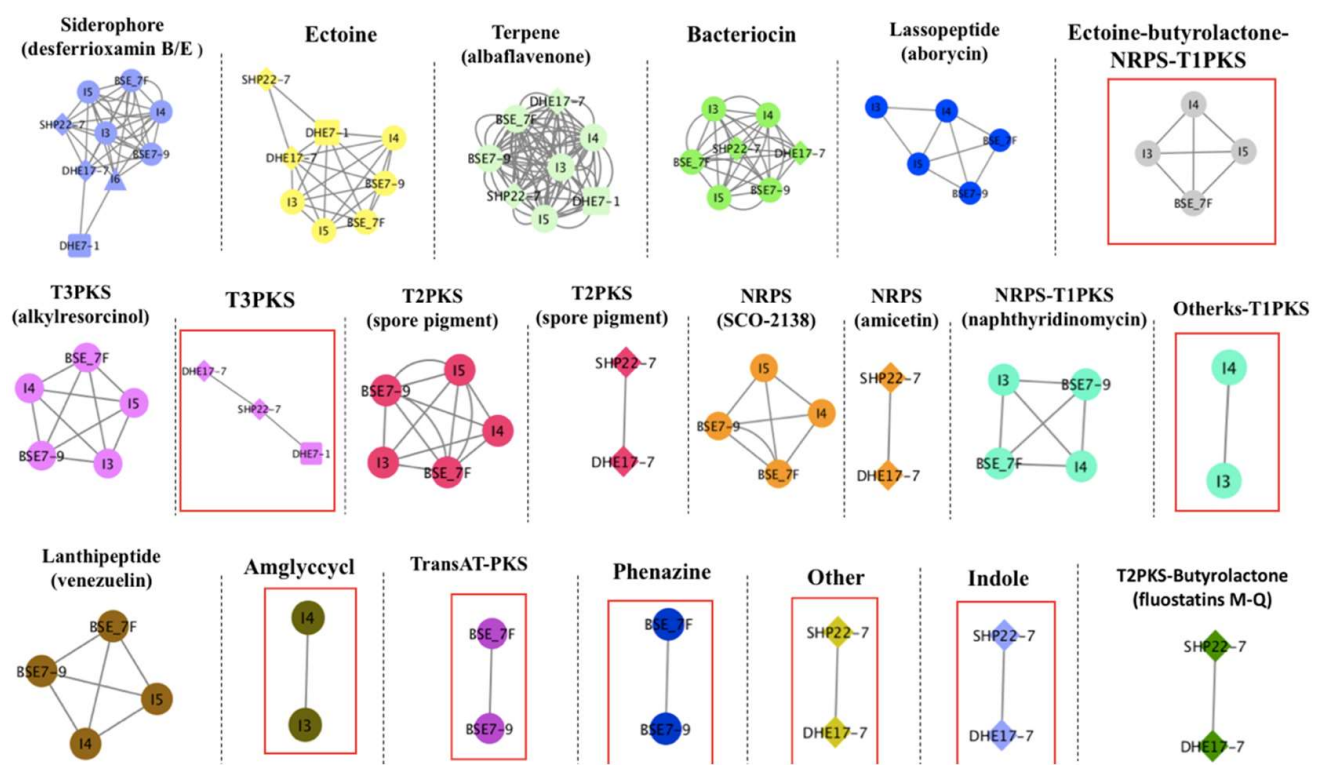

Figure 4. Similarity network of the predicted biosynthetic gene clusters (BGCs) of the nine Indonesian Streptomyces strains. Shared similar BGCs are indicated by a connected line. Each node represents a specific BGC type (labeled with different colors). The shape node represents the same species, i.e., clade A (SHP 22-7 and DHE 17-7) indicated with diamond, clade B (I4, I5, BSE 7F, and BSE 7-9) shown with ellipse, clade C (DHE 7-1) with a cube, and clade D (I6) indicated with a triangle. For BGCs with similarities above $60 \%$, the predicted biosynthetic products are given in brackets below the denomination of the BGC type, and for BGCs with similarities less than $60 \%$ the predicted biosynthetic products are highlighted with red boxes.

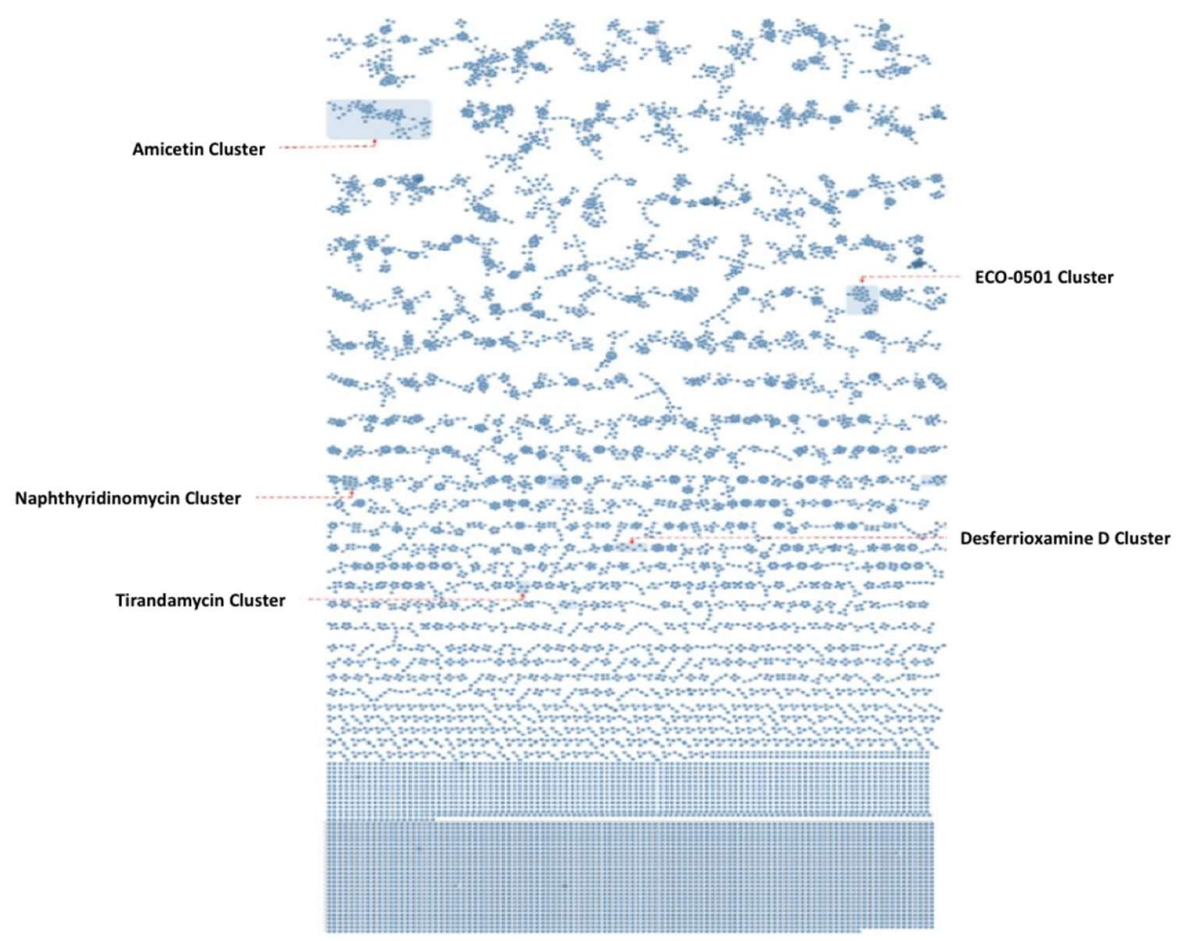


Figure 5. Molecular networking of extract and fraction samples from nine Indonesian Streptomyces strains. Molecular families containing a known substance are highlighted by blue boxes.

Table 1. Indonesian strains, isolation method, source of isolation (compare Figure 1), and most closely related species (\%) based on 16S rRNA gene sequence phylogenetic analysis with EzTaxon.

\begin{tabular}{|c|c|c|c|}
\hline $\begin{array}{c}\text { Strain (Streptomy- } \\
\text { ces sp.) }\end{array}$ & $\begin{array}{l}\text { Isolation } \\
\text { method }\end{array}$ & Source of isolation & $\begin{array}{l}\text { Most closely related spe- } \\
\text { cies based on } 16 S \text { analy- } \\
\text { sis }\end{array}$ \\
\hline SHP 22-7 & phenol & $\begin{array}{l}\text { Soil under a keta- } \\
\text { pang tree (Termi- } \\
\text { nalia catappa) from } \\
\text { Desa Meok (B1), } \\
\text { Enggano Island }\end{array}$ & $\begin{array}{c}\text { Streptomyces rochei } \\
\text { NBRC } 12908^{\mathrm{T}}(99.59 \%)\end{array}$ \\
\hline SHP 20-4 & phenol & $\begin{array}{l}\text { Soil under a kina } \\
\text { tree (Cinchona sp.), } \\
\text { Desa Banjarsari } \\
\text { (B2), Enggano Is- } \\
\text { land }\end{array}$ & $\begin{array}{l}\text { Streptomyces hydrogenans } \\
\text { NBRC } 12908^{\mathrm{T}}(99.68 \%)\end{array}$ \\
\hline SHP 2-1 & phenol & $\begin{array}{l}\text { Soil under a hiyeb } \\
\text { tree (Artocarpus } \\
\text { elastica) near Bak } \\
\text { Blau water spring, } \\
\text { Desa Meok (B3), } \\
\text { Enggano Island }\end{array}$ & $\begin{array}{l}\text { Streptomyces griseoluteus } \\
\text { NBRC } 13375^{\mathrm{T}}(98.96 \%)\end{array}$ \\
\hline DHE 17-7 & dry heat & $\begin{array}{l}\text { Soil under a ficus } \\
\text { tree (Ficus sp.), } \\
\text { Desa Boboyo (B4), } \\
\text { Enggano Island }\end{array}$ & 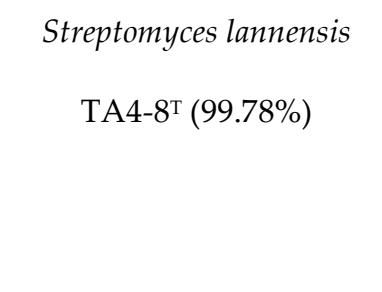 \\
\hline
\end{tabular}




\begin{tabular}{|c|c|c|c|}
\hline DHE 12-3 & dry heat & $\begin{array}{l}\text { Soil under a cem- } \\
\text { pedak tree (Artocar- } \\
\text { pus integer), Desa } \\
\text { Boboyo (B4), Eng- } \\
\text { gano Island }\end{array}$ & $\begin{array}{l}\text { Streptomyces coerulescens } \\
\qquad \text { ISP } 51446^{\mathrm{T}}(98.87 \%)\end{array}$ \\
\hline DHE 7-1 & dry heat & $\begin{array}{l}\text { Soil under a terok } \\
\text { tree (Artocarpus } \\
\text { elastica), desa Bo- } \\
\text { boyo (B4), Enggano } \\
\text { Island }\end{array}$ & $\begin{array}{l}\text { Streptomyces adustus WH- } \\
\qquad 9^{\mathrm{T}}(99.59 \%)\end{array}$ \\
\hline DHE 6-7 & dry heat & $\begin{array}{l}\text { Soil under forest } \\
\text { snake fruit tree (Sa- } \\
\text { lacca sp.), Desa Ma- } \\
\text { lakoni (B5), Eng- } \\
\text { gano Island }\end{array}$ & $\begin{array}{l}\text { Streptomyces parvulus } \\
\text { NBRC } 13193^{\mathrm{T}}(98.55 \%)\end{array}$ \\
\hline DHE 5-1 & dry heat & $\begin{array}{l}\text { Soil under a banana } \\
\text { tree (Musa sp.), } \\
\text { Desa Banjar sari } \\
\text { (B2), Enggano Is- } \\
\text { land }\end{array}$ & $\begin{array}{l}\text { Streptomyces parvulus } \\
\text { NBRC } 13193^{\mathrm{T}}(99.79 \%)\end{array}$ \\
\hline BSE 7-9 & $\begin{array}{c}\text { NBRC } \\
\text { medium } \\
802\end{array}$ & $\begin{array}{l}\text { Mangrove sedi- } \\
\text { ment near plant } \\
\text { rhizosphere, Kuta } \\
\text { (C1), Bali Island }\end{array}$ & $\begin{array}{l}\text { Streptomyces bellus ISP } \\
\qquad 5185^{\mathrm{T}}(99.06 \%)\end{array}$ \\
\hline BSE 7F & $\begin{array}{c}\text { NBRC } \\
\text { medium } \\
802\end{array}$ & $\begin{array}{l}\text { Mangrove sedi- } \\
\text { ment near plant }\end{array}$ & $\begin{array}{l}\text { Streptomyces matensis } \\
\text { NBRC } 12889^{\mathrm{T}}(99.72 \%)\end{array}$ \\
\hline
\end{tabular}




\begin{tabular}{|c|c|c|c|}
\hline & & $\begin{array}{l}\text { rhizosphere, Kuta } \\
\text { (C1), Bali Island }\end{array}$ & \\
\hline I3 & $\begin{array}{c}\mathrm{HV}+ \\
\text { Chlorine } \\
1 \%\end{array}$ & $\begin{array}{l}\text { Mangrove sedi- } \\
\text { ment from Pantai } \\
\text { Tanjung Kelor, Sek- } \\
\text { otong (D2), West } \\
\text { Lombok Island }\end{array}$ & $\begin{array}{l}\text { Streptomyces longispo- } \\
\text { roruber NBRC } 13488^{\mathrm{T}} \\
\qquad(99.23 \%)\end{array}$ \\
\hline I4 & $\begin{array}{c}\mathrm{HV}+ \\
\text { Chlorine } \\
1 \%\end{array}$ & $\begin{array}{l}\text { Mangrove sedi- } \\
\text { ment from Pantai } \\
\text { Tanjung Kelor, Sek- } \\
\text { otong (D2), West } \\
\text { Lombok Island }\end{array}$ & $\begin{array}{c}\text { Streptomyces griseoincar- } \\
\text { natus LMG } 19316^{\mathrm{T}} \\
(99.89 \%)\end{array}$ \\
\hline I5 & $\begin{array}{c}\mathrm{HV}+ \\
\text { Chlorine } \\
1 \%\end{array}$ & $\begin{array}{l}\text { Mangrove sedi- } \\
\text { ment from Pantai } \\
\text { Tanjung Kelor, Sek- } \\
\text { otong (D2), West } \\
\text { Lombok Island }\end{array}$ & $\begin{array}{l}\text { Streptomyces viridodiasticus } \\
\text { NBRC13106 }{ }^{\mathrm{T}}(99.31 \%)\end{array}$ \\
\hline I6 & $\begin{array}{c}\mathrm{HV}+ \\
\text { Chlorine } \\
1 \%\end{array}$ & $\begin{array}{l}\text { Mangrove sedi- } \\
\text { ment from Pantai } \\
\text { Tanjung Kelor, } \\
\text { Sekotong (D2), } \\
\text { West Lombok Is- } \\
\text { land }\end{array}$ & $\begin{array}{l}\text { Streptomyces spongiicola } \\
\text { HNM0071' (99.78\%) }\end{array}$ \\
\hline I8 & $\mathrm{HV}$ & $\begin{array}{l}\text { Sea sands from } \\
\text { Pantai Koeta (D3), } \\
\text { Lombok Island }\end{array}$ & $\begin{array}{l}\text { Streptomyces smyrnaeus } \\
\qquad \mathrm{SM}^{2} 01^{\mathrm{T}}(98.44 \%)\end{array}$ \\
\hline
\end{tabular}




\begin{tabular}{|l|c|c|c|}
\hline I9 & HV & Sea sands from & Streptomyces gancidicus \\
& & Pantai Koeta (D3), & NBRC $15412^{\mathrm{T}}(98.82 \%)$ \\
& Lombok Island & \\
\hline
\end{tabular}

Table 2. Data from pairwise comparisons between genome sequences from nine Indonesian strains and their closest related strains based on dDDH analysis.

\begin{tabular}{|c|c|c|}
\hline Query strain & Subject strain & $\operatorname{dDDH}\left(d_{4}\right.$, in $\left.\%\right)$ \\
\hline I3 & $\mathrm{I} 4$ & 99.6 \\
\hline BSE 7-9 & BSE 7F & 95.7 \\
\hline DHE 17-7 & SHP 22-7 & 86.7 \\
\hline $\mathrm{I} 4$ & I5 & 82.6 \\
\hline I3 & I5 & 82.5 \\
\hline BSE 7F & I5 & 78.4 \\
\hline BSE 7-9 & I5 & 78.4 \\
\hline BSE 7-9 & I4 & 77.2 \\
\hline BSE 7F & $\mathrm{I} 4$ & 77.2 \\
\hline BSE 7F & I3 & 77 \\
\hline BSE 7-9 & $\mathrm{I} 3$ & 77 \\
\hline I6 & Streptomyces spongiicola HNM0071 & 51.5 \\
\hline SHP 22-7 & Streptomyces luteus TRM 45540 & 43.6 \\
\hline DHE 17-7 & Streptomyces luteus TRM 45540 & 40.3 \\
\hline DHE 7-1 & Streptomyces bungoensis DSM 41781 & 32.3 \\
\hline $\mathrm{I} 3$ & Streptomyces capillispiralis DSM 41695 & 31.5 \\
\hline BSE 7-9 & Streptomyces capillispiralis DSM 41695 & 31.5 \\
\hline I5 & Streptomyces capillispiralis DSM 41695 & 31.5 \\
\hline $\mathrm{I} 4$ & Streptomyces capillispiralis DSM 41695 & 31.4 \\
\hline BSE 7F & Streptomyces capillispiralis DSM 41695 & 31.4 \\
\hline
\end{tabular}


Table 3. List of Indonesian actinomycetes strains with number and type of BGCs as predicted by antiSMASH analysis.

\begin{tabular}{|l|l|l|l|l|l|l|l|l|}
\hline Strain & $\begin{array}{l}\text { Total } \\
\text { BGCs }\end{array}$ & PKS & NRPS & $\begin{array}{l}\text { Hybrid } \\
\text { BGC }\end{array}$ & Terpene & RiPP & $\begin{array}{l}\text { Sider- } \\
\text { o- } \\
\text { phore }\end{array}$ & Others \\
\hline DHE 17-7 & 30 & 6 & 7 & - & 6 & 3 & 3 & 5 \\
\hline DHE 7-1 & 27 & 6 & 6 & 3 & 5 & - & 3 & 4 \\
\hline SHP 22-7 & 25 & 5 & 6 & 1 & 4 & 1 & 2 & 6 \\
\hline I4 & 19 & 3 & 2 & - & 4 & 4 & 2 & 5 \\
\hline I3 & 17 & 4 & 2 & 1 & 4 & 2 & 2 & 3 \\
\hline I5 & 19 & 3 & 2 & 1 & 4 & 4 & 2 & 3 \\
\hline BSE 7F & 23 & 3 & 1 & 4 & 5 & 4 & 2 & 4 \\
\hline BSE 7-9 & 22 & 4 & 2 & 3 & 4 & 1 & 2 & 6 \\
\hline & 24 & 3 & 6 & 1 & 2 & 1 & 2 & 9 \\
\hline
\end{tabular}

Table 4. Presence (grey color) and absence (white color) of BGCs in nine Indonesian strains as predicted by antiSMASH analysis with similarity above $60 \%$.

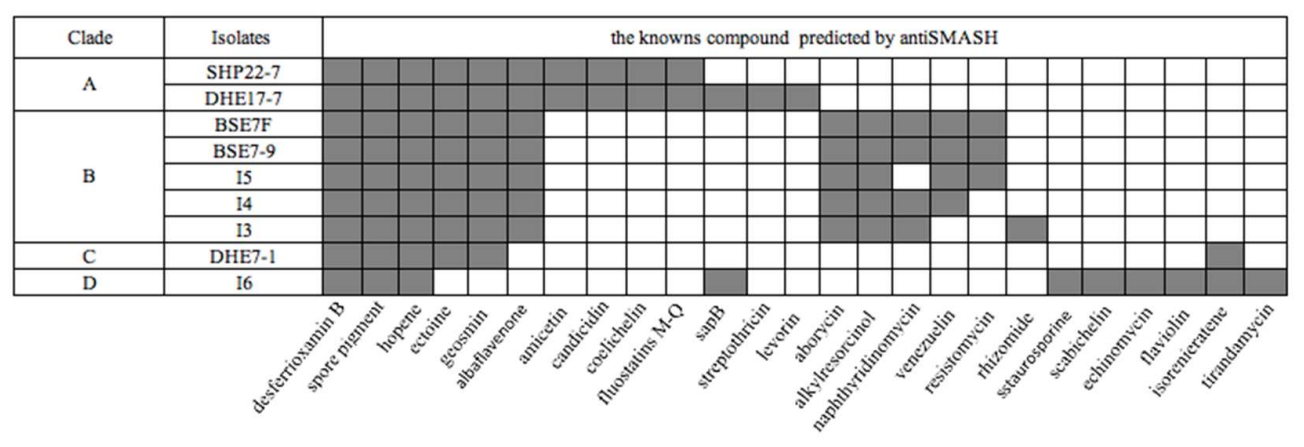


Table 5. Correlation between known compounds and BGC distribution in the nine Indonesian strains. A checkmark $(\sqrt{ })$ indicates identified BGC in the strain studied, a question mark (?) indicates that BGC is not identified in the strain studied, and a minus sign (-) indicates the compound is not present in the medium.

\begin{tabular}{|c|c|c|c|c|c|}
\hline \multirow{2}{*}{$\begin{array}{l}\text { Ion cluster name } \\
\text { (molecular for- } \\
\text { mula) }\end{array}$} & \multirow{2}{*}{$\begin{array}{c}\text { m/z litera- } \\
\text { ture } \\
\text { (m/z meas- } \\
\text { ured) }\end{array}$} & \multirow{2}{*}{ adduct } & \multicolumn{2}{|c|}{$\begin{array}{l}\text { Main producer and me- } \\
\text { dia type }\end{array}$} & \multirow[t]{2}{*}{$\begin{array}{l}\text { BGC iden- } \\
\text { tified }\end{array}$} \\
\hline & & & Solid & Liquid & \\
\hline $\begin{array}{l}\text { Desferrioxamine B } \\
\qquad\left(\mathrm{C}_{25} \mathrm{H}_{48} \mathrm{~N}_{6} \mathrm{O}_{8}\right)\end{array}$ & $\begin{array}{c}560.684 \\
(613.26483)\end{array}$ & {$[\mathrm{M}+2 \mathrm{H}+\mathrm{Fe}]^{+}$} & $\begin{array}{l}\text { SHP 22-7; } \\
\text { I3; I4; I6 }\end{array}$ & - & $\sqrt{ }$ \\
\hline $\begin{array}{c}\text { Desferrioxamine D } \\
\qquad\left(\mathrm{C}_{27} \mathrm{H}_{50} \mathrm{~N}_{6} \mathrm{O}_{9}\right)\end{array}$ & $\begin{array}{c}602.720 \\
(655.27821)\end{array}$ & {$[\mathrm{M}+2 \mathrm{H}+\mathrm{Fe}]^{+}$} & $\begin{array}{l}\text { SHP 22-7; } \\
\text { I3; I4; I6 }\end{array}$ & - & $\sqrt{ }$ \\
\hline $\begin{array}{l}\text { Naphthyridinomy- } \\
\operatorname{cin}\left(\mathrm{C}_{21} \mathrm{H}_{27} \mathrm{~N}_{3} \mathrm{O}_{6}\right)\end{array}$ & $\begin{array}{c}417.456 \\
(417.19014)\end{array}$ & {$[\mathrm{M}+\mathrm{H}]^{+}$} & I3; I4; I5 & $\begin{array}{l}\text { BSE 7F; } \\
\text { BSE 7-9; } \\
\text { I5 }\end{array}$ & $\sqrt{ }$ \\
\hline $\begin{array}{c}\text { Amicetin } \\
\left(\mathrm{C}_{29} \mathrm{H}_{42} \mathrm{~N}_{6} \mathrm{O}_{9}\right)\end{array}$ & $\begin{array}{c}618.679 \\
(618.30078) \\
\end{array}$ & {$[\mathrm{M}+\mathrm{H}]^{-}$} & - & $\begin{array}{l}\text { SHP 22-7; } \\
\text { DHE 17-7 }\end{array}$ & $\sqrt{ }$ \\
\hline $\begin{array}{l}\text { Antimycin } \\
\left(\mathrm{C}_{27} \mathrm{H}_{38} \mathrm{~N}_{2} \mathrm{O}_{9}\right)\end{array}$ & $\begin{array}{c}534.599 \\
(534.25837\end{array}$ & {$[\mathrm{M}+\mathrm{H}]^{+}$} & - & BSE 7F & $\sqrt{ }$ \\
\hline $\begin{array}{c}\text { ECO-0501 } \\
\left(\mathrm{C}_{48} \mathrm{H}_{68} \mathrm{~N}_{4} \mathrm{O}_{10}\right)\end{array}$ & $\begin{array}{c}837.1 \\
(835.4861)\end{array}$ & {$[\mathrm{M}+\mathrm{H}]^{-}$} & - & DHE 17-7 & $?$ \\
\hline $\begin{array}{c}\text { MY336-a } \\
\left(\mathrm{C}_{13} \mathrm{H}_{19} \mathrm{NO}_{4}\right)\end{array}$ & $\begin{array}{c}253.1314 \\
(253.13182)\end{array}$ & {$[\mathrm{M}+\mathrm{H}]^{+}$} & - & BSE 7-9 & $?$ \\
\hline $\begin{array}{c}\text { Echinomycin } \\
\left(\mathrm{C}_{51} \mathrm{H}_{64} \mathrm{~N}_{12} \mathrm{O}_{12} \mathrm{~S}_{2}\right)\end{array}$ & $\begin{array}{c}1101.257 \\
(1100.42199)\end{array}$ & {$[\mathrm{M}+\mathrm{H}]^{-}$} & I6 & - & $\sqrt{ }$ \\
\hline $\begin{array}{c}\text { Tirandamycin A } \\
\left(\mathrm{C}_{22} \mathrm{H}_{27} \mathrm{NO}_{7}\right)\end{array}$ & $\begin{array}{c}417.4523 \\
(417.2063) \\
\end{array}$ & {$[\mathrm{M}+\mathrm{H}]^{+}$} & I6 & - & $\sqrt{ }$ \\
\hline $\begin{array}{l}\text { Staurosporine } \\
\left(\mathrm{C}_{51} \mathrm{H}_{68} \mathrm{~N}_{12} \mathrm{O}_{14} \mathrm{~S}_{2}\right)\end{array}$ & $\begin{array}{c}1136.4419 \\
(1137.4504)\end{array}$ & {$[\mathrm{M}+\mathrm{H}]^{+}$} & I6 & & $\sqrt{ }$ \\
\hline
\end{tabular}

Table 6. Overview of the analog and putative compound identified for the nine Indonesian Streptomyces strains. A minus sign (-) indicates that the compound is not present in the medium.

\begin{tabular}{|c|c|c|c|c|}
\hline $\begin{array}{c}\text { Ion cluster name } \\
\text { (molecular formula) }\end{array}$ & $\begin{array}{c}\text { m/z meas- } \\
\text { ured }\end{array}$ & adduct & \multicolumn{2}{|c|}{ Main producer and media } \\
\cline { 3 - 4 } & & & Solid & Liquid \\
\hline $\begin{array}{c}\text { Desferrioxamine B analog } \\
\left(\mathrm{C}_{28} \mathrm{H}_{52} \mathrm{~N}_{6} \mathrm{O} 8\right)\end{array}$ & 653.261 & {$[\mathrm{M}+2 \mathrm{H}+\mathrm{Fe}]^{+}$} & SHP 22-7 & \\
\hline $\begin{array}{c}\text { Desferrioxamine } \\
\left(\mathrm{C}_{26} \mathrm{H}_{48} \mathrm{~N}_{6} \mathrm{O}_{8}\right)\end{array}$ & 626.323 & {$[\mathrm{M}+2 \mathrm{H}+\mathrm{Fe}]^{+}$} & $\mathrm{I3} ; \mathrm{I} 4 ; \mathrm{I} 6$ & \\
\hline
\end{tabular}




\begin{tabular}{|c|c|c|c|c|}
\hline $\begin{array}{c}\text { Antimycin analog } 1 \\
\left(\mathrm{C}_{29} \mathrm{H}_{42} \mathrm{~N}_{2} \mathrm{O}_{9}\right)\end{array}$ & 562.289 & {$[\mathrm{M}+\mathrm{H}]^{-}$} & - & BSE 7F \\
\hline $\begin{array}{c}\text { Antimycin analog } 2 \\
\left(\mathrm{C}_{28} \mathrm{H}_{40} \mathrm{~N}_{2} \mathrm{O}_{9}\right)\end{array}$ & 548.273 & {$[\mathrm{M}+\mathrm{H}]^{-}$} & - & BSE 7F \\
\hline $\begin{array}{c}\text { Antimycin analog } 3 \\
\left(\mathrm{C}_{26} \mathrm{H}_{36} \mathrm{~N}_{2} \mathrm{O}_{9}\right)\end{array}$ & 520.242 & {$[\mathrm{M}+\mathrm{H}]^{-}$} & - & BSE 7F \\
\hline $\begin{array}{c}\text { Antimycin analog } 4 \\
\left(\mathrm{C}_{25} \mathrm{H}_{34} \mathrm{~N}_{2} \mathrm{O}_{9}\right)\end{array}$ & 506.226 & {$[\mathrm{M}+\mathrm{H}]^{-}$} & - & BSE 7F \\
\hline $\begin{array}{c}\text { Putative ion cluster } 1 \\
{[\mathrm{M}+\mathrm{H}]^{+}}\end{array}$ & 362.148 & $\begin{array}{c}\text { I3; I4; BSE } \\
7 \mathrm{~F}\end{array}$ & BSE 7-9 \\
\hline $\begin{array}{c}\text { Putative ion cluster } 2 \\
{[\mathrm{M}+2 \mathrm{H}]^{2+}}\end{array}$ & $\begin{array}{c}\text { I3; I5; I4; } \\
\text { BSE 7F }\end{array}$ & - \\
\hline Putative ion cluster 3 & 1194.554 & {$[\mathrm{M}+2 \mathrm{H}]^{2+}$} & $\begin{array}{c}\text { I3; I5; I4; } \\
\text { BSE 7F }\end{array}$ & - \\
\hline Putative ion cluster 4 & 553.174 & {$[\mathrm{M}+\mathrm{H}]^{+}$} & - & I6 \\
\hline Putative ion cluster 5 & 442.287 & {$[\mathrm{M}+2 \mathrm{H}]^{+}$} & - & DHE 17-7 \\
\hline Putative ion cluster 6 & 449.294 & {$[\mathrm{M}+2 \mathrm{H}]^{+}$} & - & DHE 17-7 \\
\hline Putative ion cluster 7 & 955.566 & {$\left[\mathrm{M}-\mathrm{H}+\mathrm{HCO}{ }_{2} \mathrm{H}\right]$} & - & DHE 17-7 \\
\hline Putative ion cluster 8 & 638.508 & {$[\mathrm{M}-\mathrm{H}+\mathrm{MeOH}]$} & - & DHE 17-7 \\
\hline
\end{tabular}

\section{Materials and Methods}

\subsection{Sample Collection and Treatment}

Soil samples were collected from Enggano Island (5 22' 57.0792" S, 102 ${ }^{\circ} 13^{\prime} 28.2792 " \mathrm{E}$ ), Indonesia, in December 2015 (Figure 1B). Marine samples were collected from marine sediments from Bali Island ( $8^{\circ} 43^{\prime} 5.5^{\prime \prime} \mathrm{S}, 115^{\circ} 10^{\prime}$ 7.8" E), Indonesia, in May 2014 (Figure $1 C)$, and Lombok Island West Nusa Tenggara ( $8^{\circ} 24^{\prime} 17.133^{\prime \prime} S, 116^{\circ} 15^{\prime} 57.228^{\prime \prime}$ E), Indonesia, in May 2017 (Figure 1D). Soil and sediment samples were taken aseptically from 10 $\mathrm{cm}$ depth of soil samples and the center of sediment in mangrove and tidal area. Soil and sediment samples were transferred into sterile $50 \mathrm{ml}$ conical tubes and placed on ice and then stored at $4^{\circ} \mathrm{C}$ until further treatment.

\subsection{Isolation of Actinomycetes}

Isolation and enumeration of actinomycetes were done using a serial dilution of Humic Acid-Vitamin (HV) medium [48] and/or NBRC No. 802 Medium [49] by using direct method [50], dry heat method [51], and phenol method [51]. In direct method, An airdried soil sample or marine sediment was ground in a mortar and heated in a hot-air oven at $110^{\circ} \mathrm{C}$ for $30 \mathrm{~min}$. One gram of the heated samples was transferred to $10 \mathrm{ml}$ of sterile water and mixed for $2 \mathrm{~min}$, then diluted with sterile water to $10^{-1}, 10^{-2}, 10^{-3}$ times. Two hundred $\mu \mathrm{l}$ of each dilution was inoculated on isolation medium agar of HV [48] or NBRC No. 802 Medium [49] with or without the addition of $1 \% \mathrm{NaCl}$. The inoculated plates were 
incubated for $2-4$ weeks at $28^{\circ} \mathrm{C}$. The colonies showing the Streptomyces morphological characteristics were selected and streaked on fresh plates of the modified Streptomyces International Project $2(\mathrm{ISP} 2 \bumpeq$ Y YM) agar [52]. The cultures were resuspended in sterile $0.9 \%$ $(\mathrm{w} / \mathrm{v})$ saline supplemented with $15 \%(\mathrm{v} / \mathrm{v})$ glycerol and stored at $-80^{\circ} \mathrm{C}$. This dry heat method [51] was used to isolate heat-tolerant actinomycetes spores. In dry heat method, the soil or sediment samples were incubated at $100^{\circ} \mathrm{C}$ for $40 \mathrm{~min}$ and then cooled to $28^{\circ} \mathrm{C}$ in a desiccator. The samples were distributed on HV medium agar plates with a spatula tip and incubated at $28^{\circ} \mathrm{C}$ for two to three weeks. The phenol method was used to select for spores, which survive in the presence of phenol. One $\mathrm{ml}$ of $10^{-1}$ dilution of one gram of oven-dried soil or marine sample was transferred to $9 \mathrm{ml}$ of sterile $5 \mathrm{mM}$-phosphate buffer ( $\mathrm{pH} 7.0$ ) containing phenol at a final concentration of $1.5 \%$. The sample was then heated and diluted in serial dilution $\left(10^{-1}, 10^{-2}, 10^{-3}\right) .100$ or $200 \mu$ of each dilution were spread over the surface of HV medium agar plates and incubated for two to four weeks at $28^{\circ} \mathrm{C}$.

\subsection{Antimicrobial Bioassays}

The preliminary screening of actinomycetal strains for antimicrobial activity was performed using the agar plug diffusion method (see Supplementary for test plate preparation). Gram-positive (B. subtilis ATCC6051, M. luteus, and S. carnosus TM300) and Gramnegative bacteria (E. coli K12 W3110 and P. fluorescens) were chosen as test organisms. The isolates were spread evenly over the agar plate surface of soya flour mannitol medium (MS) (mannitol $20 \mathrm{~g}$, soy flour (full fat) $20 \mathrm{~g}$, agar $16 \mathrm{~g}$ in $1 \mathrm{~L}$ of distilled water) [80] and incubated for 10 days at $28^{\circ} \mathrm{C}$. Agar discs of the 10 days inoculum were cut aseptically with a cork borer ( $9 \mathrm{~mm}$ diameter) and placed on the bioassay test plate. Bioassays to determine optimal cultivation conditions in the liquid culture were examined using a disc diffusion assay against the test Gram-positive (B. subtilis ATCC6051, M. luteus, and S. carnosus TM300) and Gram-negative bacteria (E. coli K12 W3110 and P. fluorescens). Ten $\mu 1$ methanolic extract obtained from liquid cultures of the actinomycetal strains were pipetted on a filter disc $(6 \mathrm{~mm})$ and then placed on the respective test plates. $5 \mu$ l kanamycin $(50 \mu \mathrm{g} / \mathrm{ml})$ was used as positive control and $10 \mu \mathrm{l}$ methanol as a negative control.

The bioassay plates were incubated overnight at $37^{\circ} \mathrm{C}$ for B. subtilis, E. coli, and S. carnosus and at $28^{\circ} \mathrm{C}$ for $M$. luteus and $P$. fluorescens to allow the test organisms growth. The antimicrobial activity of the isolates was assessed by measuring the diameter of the inhibition zone $(\mathrm{mm})$ around the agar plug or the discs. All bioassay tests were carried out as three independent biological replicates.

\subsection{Isolation of Genomic DNA and 16S Phylogenetic Analysis}

For isolation of genomic DNA, the producer strains were grown for two days in $50 \mathrm{ml}$ of $\mathrm{R} 5$ medium at $30^{\circ} \mathrm{C}$ [80]. The genomic DNA was extracted and purified with the Nucleospin ${ }^{\circ}$ Tissue kit from Macherey-Nagel (catalog number 740952.50) following the standard protocol from the manufacturer. The DNA was applied as a PCR template for 16S rRNA gene amplification using polymerase chain reaction (PCR). Primers used for PCR were 27Fbac (5'-AGAGTTTGATCMTGGCTCAG-3') and 1492Runi (5'-TACGGTTACCTTACGACTT-3'). The PCR amplicons were sub cloned into the cloning vector pDrive (Qiagen) using basic DNA manipulation procedures as previously described by Sambrook et al. [108]. The respective 16S fragments were sequenced at MWG Eurofins (Ebersberg, Germany) with primers $27 \mathrm{Fbac}$. The $16 \mathrm{~S}$ sequence data were analyzed using the EzTaxon database (https://www.ezbiocloud.net).

\subsection{Phylogenomics and Genome Mining Analysis}

For phylogenomic and genome mining studies, full genome sequence data have been obtained as reported previously [57-59]. Genomic DNA was isolated to construct a 10 to 20- 
$\mathrm{kb}$ paired-end library for sequencing by Macrogen (Seoul, South Korea) with the Pacific Biosciences RS II technology (Pacbio). The genome was assembled using Hierarchical Genome Assembly (HGAP) V.3. and annotated with Prokka version 1.12b and the NCBI Prokaryotic Genome Annotation Pipeline (PGAP). The phylogenomic analysis of the nine selected strains was carried out with the Type (Strain) Genome Server (TYGS), a free bioinformatics tool (https://tygs.dsmz.de/) for whole genome-based taxonomic analysis [63]. The identification of potential biosynthesis gene clusters (BGCs) was accomplished by analyzing the genome sequences with antiSMASH version 5.0 [44]. The antiSMASH results were further analyzed using the BiG-SCAPE platform [77] to cluster the predicted BGCs into gene cluster families (GCFs) based on their sequences and Pfam protein families similarities [78]. BiG-SCAPE was conducted on global mode with default parameters [77], with the exception of the raw distance cutoff and the "--mix" parameter. Raw distance cutoff was set to 0.4 to ensure that even clusters with a pairwise distance higher than 0.3 (the default) are included in the output. The resulting network of BiG-SCAPE was visualized with Cytoscape version 3.7.2 [81].

\subsection{Cultivation Conditions for Optimal Compound Production of nine Indonesian Strains}

To determine optimal cultivation conditions in liquid culture, the nine Indonesian actinomycetes strains, SHP 22-7, DHE 17-7, DHE 7-1, BSE 7-9, BSE 7F, I3, I4, I5, and I6, were each cultivated in $50 \mathrm{ml}$ inoculum medium (NL410) in 500-ml Erlenmeyer flasks (with steel springs) on an orbital shaker ( $180 \mathrm{rpm})$ at $28^{\circ} \mathrm{C}$. After 48 hours, $10 \mathrm{ml}$ of preculture were inoculated into $100 \mathrm{ml}$ of twelve different production medium (SGG, YM, OM, R5, MS, TSG, NL19, NL300, NL330, NL500, NL550, NL800 (Table S2) and cultivated for 48-168 hours. Cell culture samples were harvested at different time points (48, 72, 96, and $168 \mathrm{~h}$ ). $5 \mathrm{ml}$ of each cell culture sample was extracted with the same volume of ethyl acetate (EtOAc) for $30 \mathrm{~min}$ at room temperature. The EtOAc was dried in a rotary evaporator and suspended in a total volume of $0.75 \mathrm{ml}$ methanol. The methanolic extracts were used for bioassay experiments. The culture extract samples, which yielded the largest zone of inhibition in the bioassays against the test organisms, were used for further compound identification analysis. To determine optimal cultivation conditions on solid culture, the nine Indonesian strains were each spread on $100 \mathrm{ml}$ agar plates consisting of the respective above mentioned cultivation media and then incubated for seven to ten days at $28^{\circ} \mathrm{C}$ until spore formation was visible on agar plates. The overgrown agar was then used for bioassay experiments and further compound identification analysis.

\subsection{Sample Preparation for Chemical Identification}

For chemical identification in the liquid sample, the nine Indonesian isolates were each cultivated in $50 \mathrm{ml}$ of NL410 medium. After 48 hours, $10 \mathrm{ml}$ of the preculture were inoculated into $100 \mathrm{ml}$ of optimal production medium. The $100 \mathrm{ml}$ whole broth of each cell culture was extracted as that described above. Then, the extracts were used for further experiment. For chemical identification from samples grown on solid medium, overgrown agar was cut into pieces and transferred to $50 \mathrm{ml}$ Falcon tubes. Falcon tubes were centrifuged at 13,000 rpm for $30 \mathrm{~min}$ at room temperature. The aqueous phase was concentrated to $1 / 5$ of the original volume in the Genevac Centrifugal Evaporator EZ-2 Elite (SP Scientific). The concentrated aqueous phase was used for further chemical profiling.

The culture extract samples obtained from liquid medium extraction and the aqueous phase of the solid medium extraction were separated by Solid Phase Extraction (SPE) columns. The columns were washed twice with $2 \mathrm{ml}$ methanol, and $2 \mathrm{ml}$ distilled water for activating the columns. The samples were prepared by adding $100 \%$ methanol to the culture extract samples and the aqueous phase until the samples were dissolved completely. The methanolic samples were applied onto the activated columns with a flow rate of 2 $\mathrm{ml} / \mathrm{min}$. The column was washed twice with distilled water. The column was eluted consecutively with $2 \mathrm{ml}$ of $100 \%$ methanol, 50\% methanol, and distilled water. Samples from 
the elution column were defined as fractions. The column was eluted with $100 \%$ methanol as the $100 \%$ fraction, with $50 \%$ methanol as the $50 \%$ fraction, and distilled water as the distilled water fraction. The fractions were dried in the Genevac EZ-2 Elite (SP Scientific) and then dissolved with $0.5 \mathrm{ml}$ methanol. The crude extracts and all fractions were analyzed with HPLC and High-Resolution Mass Spectrometry (HRMS).

\subsection{HPLC-HRMS/MS analysis}

The HRMS analysis was carried out on MaXis 4G instrument (Bruker Daltonics) coupled to an Ultimate 3000 HPLC (Thermo Fisher Scientific). HPLC-method was applied as follows: the spectrometer using a gradient (solvent A: $0.1 \%$ formic acid (FA) in $\mathrm{H} 2 \mathrm{O}$, and solvent B: $0.06 \%$ formic acid in acetonitrile), a gradient of $10 \%$ to $100 \%$ B in $45 \mathrm{~min}, 100 \%$ $\mathrm{B}$ for an additional $10 \mathrm{~min}$, using a flow rate of $0.3 \mathrm{ml} / \mathrm{min} ; 5 \mu \mathrm{l}$ injection volume and UV detector (UV/VIS) wavelength monitoring at 210, 254, 280, and $360 \mathrm{~nm}$. The separation was carried out on a Nucleoshell $2.7 \mu \mathrm{m} 150 \times 2 \mathrm{~mm}$ column (Macherey-Nagel), and the range for MS acquisition was $\mathrm{m} / \mathrm{z} 100-1800$. A capillary voltage of $4500 \mathrm{~V}$, nebulizer gas pressure (nitrogen) of 2 (1.6) bar, ion source temperature of $200^{\circ} \mathrm{C}$, the dry gas flow of 9 (7) L/min source temperature, and spectral rates of $3 \mathrm{~Hz}$ for MS1 and $10 \mathrm{~Hz}$ for MS${ }^{2}$ were used. For acquiring MS/MS fragmentation, the ten most intense ions per MS1 were selected for subsequent collision-induced dissociation (CID) with stepped CID energy applied. The employed parameters for tandem MS were applied as previously detailed by Garg et al. in 2015 [109]. Sodium formate was used as an internal calibrant and Hexakis (2, 2-difluoroethoxy) phosphazene (Apollo Scientific Ltd, Stockport, UK) as the lock mass. Data processing was performed using Bruker Daltonics Data Analysis 4.1.

\subsection{MS/MS Molecular Networking}

Mass spectral data were analyzed using Compass Data Analysis 4.4 (Bruker Daltonik), whereas MetaboScape 3.0 (Bruker Daltonik) was consulted for molecular features selection. Raw data files were imported into MetaboScape 3.0 for the entire data treatment and pre-processing in which T-ReX 3D (Time aligned Region Complete eXtraction) algorithm is integrated for retention time alignment with an automatic detection to decompose fragments, isotopes, and adducts intrinsic to the same compound into one single feature. All the harvested ions were categorized as a bucket table with their corresponding retention times, measured $\mathrm{m} / \mathrm{z}$, molecular weights, detected ions, and their intensity within the sample. The Bucket table was prepared with an intensity threshold (1e3) for the positive measurements with a minimum peak length 3 possessing a mass range m/z $150-1800 \mathrm{Da}$. For detailed parameters employed for the MetaboScape analysis see Table S13. The features list of the pre-processed retention time range was exported from MetaboScape as a single MGF file which was in turn uploaded to the GNPS online platform where FeatureBased Molecular Network (FBMN) was created. The precursor ion mass tolerance was set to $0.03 \mathrm{Da}$ and a MS/MS fragment ion tolerance of $0.03 \mathrm{Da}$. A network was then created where edges were filtered to have a cosine score above 0.70 and more than 5 matched peaks. Further, edges between two nodes were kept in the network if and only if each of the nodes appeared in each other's respective top 10 most similar nodes. Finally, the maximum size of a molecular family was set to 100, and the lowest-scoring edges were removed from molecular families until the molecular family size was below this threshold. Cytoscape 3.5.1 was used for molecular network visualization.

\section{Conclusions}


In this study, we report on the isolation of 422 actinomycetes strains from three different unique areas in Indonesia. A combined genomics and metabolomics approach was applied on nine of the most potent antibiotic producer strains, which allowed to uncover eight so far unknown compounds. When cultivating the strains in various liquid and solid media, we found that culture conditions significantly affected the ability to produce specific compounds. Thus, the combination of both cultivation methods, solid and liquid cultivation, is a suitable approach to tap the full biosynthetic potential of actinomycetes. By phylogeny-associated genome mining studies we found that phylogenetically related species tend to have a similar BGC composition. Additional metabolomics data suggested that the ability of the strains to produce certain compounds may be influenced by the environmental conditions, where the producer strains have been derived from.

Overall, the described methodology represents an efficient strategy for drug discovery and the reported unknown compounds may serve as a basis for further drug development.

Supplementary Materials: The following are available online at www.mdpi.com/xxx/s1.

Author Contributions: S.R., S.A. isolated strains and performed preliminary bioassays; I.H. carried out phylogenetic analysis and antibiotic bioassays; I.H., J.K. performed extraction of culture broths; A.K., H.S. carried out HPLC-MS analysis, H.S. performed GNPS studies; I.H., Y.M. did genomesequence-based bioinformatic analysis, A.G. performed BiG-SCAPE analysis; Y.M. and H.G. conceived the re-search. Y.M., W.W., H.G, N.Z. supervised the work. I.H. wrote the original draft of paper, which was revised by Y.M., W.W., H.G. and N.Z and approved by all authors. All authors have read and agreed to the published version of the manuscript.

Funding: We gratefully acknowledge the funding received from the BMBF German-Indonesian cooperation project NAbaUnAk (16GW0124K) and the German Center for Infection Research (DZIF) (TTU 09.811). I.H. is grateful for the RISET-Pro scholarship program from the Indonesian Ministry for Research and Technology (World Bank Loan No. 8245-ID). A.G. is grateful for the support of the Deutsche Forschungsgemeinschaft (DFG; Project ID \# 398967434-TRR 261). S.A. is grateful for his Ph.D. scholarships (grant PKZ 91613866), generously provided by the German Academic Exchange Service (DAAD).

Institutional Review Board Statement: Not applicable

Informed Consent Statement: Not applicable

Data Availability Statement: The complete genomes sequence data were deposited at the National Center for Biotechnology (NCBI) information data base, https://www.ncbi.nlm.nih.gov/genome with the accession numbers QEQV00000000 for BSE 7F, QXMM00000000 for SHP 22-7, SAMN15691494 for DHE 7-1, SAMN15691533 for I3, SAMN15691540 for I4, SAMN15691656 for I5, SAMN15691724 for BSE 7-9, SAMN15692265 for DHE 17-7, and RHDP00000000 for I6. GNPS job data: https://gnps.ucsd.edu/ProteoSAFe/status.jsp?task=429506a1cc2c4a679b421cc455c0249b.

Acknowledgments: We thank R. Ort-Winklbauer for technical assistance and Dorothee Wistuba for support in HRMS experiments. The Ministry of Research and Technology, Republic of Indonesia through the RISET-Pro Scholarship support to I.H (World Bank Loan No. 8245-ID).

Conflicts of Interest: The authors declare no conflict of interest. The funders had no role in the design of the study; in the collection, analyses, or interpretation of data; in the writing of the manuscript, or in the decision to publish the results.

\section{References}

1. Waksman, S.A.; Woodruff, H.B. The Soil as a Source of Microorganisms Antagonistic to Disease-Producing Bacteria. J. Bacteriol. 1940, 40, 581-600, doi:10.1128/JB.40.4.581-600.1940. 
2. Kresge, N.; Simoni, R.D.; Hill, R.L. Selman Waksman: the Father of Antibiotics. J. Biol. Chem. 2004, doi:10.1016/S00219258(20)67861-9.

3. van Bergeijk, D.A.; Terlouw, B.R.; Medema, M.H.; van Wezel, G.P. Ecology and genomics of Actinobacteria: new concepts for natural product discovery. Nat. Rev. Microbiol. 2020, doi:10.1038/s41579-020-0379-y.

4. Newman, D.J.; Cragg, G.M. Natural Products as Sources of New Drugs over the Nearly Four Decades from 01/1981 to 09/2019. J. Nat. Prod. 2020, doi:10.1021/acs.jnatprod.9b01285.

5. van der Heul, H.U.; Bilyk, B.L.; McDowall, K.J.; Seipke, R.F.; van Wezel, G.P. Regulation of antibiotic production in Actinobacteria: new perspectives from the post-genomic era. Nat. Prod. Rep. 2018, 35, 575-604, doi:10.1039/c8np00012c.

6. Baltz, R. Antibiotic discovery from actinomycetes: Will a renaissance follow the decline and fall? SIM News 2005, 55, 186-196.

7. Bérdy, J. Bioactive Microbial Metabolites. J. Antibiot. (Tokyo). 2005, 58, 1-26, doi:10.1038/ja.2005.1.

8. Baltz, R.H. Natural product drug discovery in the genomic era: realities, conjectures, misconceptions, and opportunities. J. Ind. Microbiol. Biotechnol. 2019, doi:10.1007/s10295-018-2115-4.

9. Hug, J.J.; Bader, C.D.; Remškar, M.; Cirnski, K.; Müller, R. Concepts and methods to access novel antibiotics from actinomycetes. Antibiotics 2018, doi:10.3390/antibiotics7020044.

10. Sivalingam, P.; Hong, K.; Pote, J.; Prabakar, K. Extreme Environment Streptomyces: Potential Sources for New Antibacterial and Anticancer Drug Leads? Int. J. Microbiol. 2019, 2019, 5283948, doi:10.1155/2019/5283948.

11. Manivasagan, P.; Venkatesan, J.; Sivakumar, K. Pharmaceutically active secondary metabolites of marine. Microbiol. Res. 2014, 169, 262-278, doi:10.1016/j.micres.2013.07.014.

12. Abdelkader, M.S.A.; Philippon, T.; Asenjo, J.A.; Bull, A.T.; Goodfellow, M.; Ebel, R.; Jaspars, M.; Rateb, M.E. Asenjonamides A-C, antibacterial metabolites isolated from Streptomyces asenjonii strain KNN 42.f from an extreme-hyper arid Atacama Desert soil. J. Antibiot. (Tokyo). 2018, 71, 425-431, doi:10.1038/s41429-017-0012-0.

13. Lacret, R.; Oves-Costales, D.; Gómez, C.; Díaz, C.; De La Cruz, M.; Pérez-Victoria, I.; Vicente, F.; Genilloud, O.; Reyes, F. New ikarugamycin derivatives with antifungal and antibacterial properties from Streptomyces zhaozhouensis. Mar. Drugs 2015, doi:10.3390/md13010128.

14. Zhang, F.; Zhao, M.; Braun, D.R.; Ericksen, S.S.; Piotrowski, J.S.; Nelson, J.; Peng, J.; Ananiev, G.E.; Chanana, S.; Barns, K.; et al. A marine microbiome antifungal targets urgent-threat drug-resistant fungi. Science (80-. ). 2020, 370, 974-978, doi:10.1126/science.abd6919.

15. Singh, S.B.; Pelaez, F. Biodiversity, chemical diversity and drug discovery. Prog. drug Res. 2008, 65, 141,143-174, doi:10.1007/978-3-7643-8117-2_4.

16. Huffard, C.L.; Erdmann, M. V.; Gunawan, T. Geographic Priorities for Marine Biodiversity Conservation in Indonesia; 2012; ISBN 978-602-98450-6-8.

17. Convention on Biological Diversity Biodiversity Facts: Status and trends of biodiversity, including benefits from biodiversity and ecosystem services Available online: https://www.cbd.int/countries/profile/?country=id (accessed on Jan 20, 2021).

18. von Rintelen, K.; Arida, E.; Häuser, C. A review of biodiversity-related issues and challenges in megadiverse Indonesia and other Southeast Asian countries. Res. Ideas Outcomes 2017, 3, doi:10.3897/rio.3.e20860.

19. De Bruyn, M.; Stelbrink, B.; Morley, R.J.; Hall, R.; Carvalho, G.R.; Cannon, C.H.; Van Den Bergh, G.; Meijaard, E.; Metcalfe, I.; Boitani, L.; et al. Borneo and Indochina are major evolutionary hotspots for Southeast Asian biodiversity. Syst. Biol. 2014, 63, 879-901, doi:10.1093/sysbio/syu047.

20. Lohman, D.J.; de Bruyn, M.; Page, T.; von Rintelen, K.; Hall, R.; Ng, P.K.L.; Shih, H.-T.; Carvalho, G.R.; von Rintelen, T. Biogeography of the Indo-Australian Archipelago. Annu. Rev. Ecol. Evol. Syst. 2011, 42, 205-226, doi:10.1146/annurev-ecolsys102710-145001.

21. Aditiawati, P.; Yohandini, H.; Madayanti, F.; Akhmaloka Microbial diversity of acidic hot spring (kawah hujan B) in geothermal field of kamojang area, west java-indonesia. Open Microbiol. J. 2009, 3, 58-66, doi:10.2174/1874285800903010058. 
in peatland forest in Indonesia. Soil Use Manag. 2020, 36, 123-138, doi:10.1111/sum.12543.

23. Voogd, N.J. De; Cleary, D.F.R.; Pol, A.R.M.; Gomes, N.C.M. Bacterial community composition and predicted functional ecology of sponges, sediment and seawater from the thousand islands reef complex, West Java ,. 2015, 1-12, doi:10.1093/femsec/fiv019.

24. Kanti, A.; Sumerta, I.N. Diversity of Xylose Assimilating Yeast From the Island of Enggano, Sumatera, Indonesia [Keragaman Khamir Pengguna Xilose Yang Diisolasi Dari Pulau Enggano, Sumatera, Indonesia]. Ber. Biol. 2016, 15, doi:10.14203/beritabiologi.v15i3.2215.

25. Hennersdorf, P.; Kleinertz, S.; Theisen, S.; Abdul-Aziz, M.A.; Mrotzek, G.; Palm, H.W.; Saluz, H.P. Microbial diversity and parasitic load in tropical fish of different environmental conditions. PLoS One 2016, doi:10.1371/journal.pone.0151594.

26. Zam, S.I.; Agustien, A.; Djamaan, A.; Mustafa, I. The Diversity of Endophytic Bacteria from the Traditional Medicinal Plants Leaves that Have Anti-phytopathogens Activity. 2019, 9, 53-63, doi:10.11594/jtls.09.01.08.

27. Baltz, R.H. Gifted microbes for genome mining and natural product discovery. J. Ind. Microbiol. Biotechnol. 2017, 44, 573-588, doi:10.1007/s10295-016-1815-x.

28. Romano, S.; Jackson, S.A.; Patry, S.; Dobson, A.D.W. Extending the "one strain many compounds" (OSMAC) principle to marine microorganisms. Mar. Drugs 2018, 16, 1-29, doi:10.3390/md16070244.

29. Krause, J.; Handayani, I.; Blin, K.; Kulik, A.; Mast, Y. Disclosing the Potential of the SARP-Type Regulator PapR2 for the Activation of Antibiotic Gene Clusters in Streptomycetes. Front. Microbiol. 2020, doi:10.3389/fmicb.2020.00225.

30. Bode, H.B.; Bethe, B.; Höfs, R.; Zeeck, A. Big effects from small changes: Possible ways to explore nature's chemical diversity. ChemBioChem 2002, 3, 619-627, doi:10.1002/1439-7633(20020703)3:7<619::AID-CBIC619>3.0.CO;2-9.

31. Pan, R.; Bai, X.; Chen, J.; Zhang, H.; Wang, H.; Aon, J.C. Exploring Structural Diversity of Microbe Secondary Metabolites Using OSMAC Strategy : A Literature Review. 2019, 10, 1-20, doi:10.3389/fmicb.2019.00294.

32. Wu, C.; van der Heul, H.U.; Melnik, A. V.; Lübben, J.; Dorrestein, P.C.; Minnaard, A.J.; Choi, Y.H.; van Wezel, G.P. Lugdunomycin, an Angucycline-Derived Molecule with Unprecedented Chemical Architecture. Angew. Chemie - Int. Ed. 2019, doi:10.1002/anie.201814581.

33. Hussain, A.; Rather, M.A.; Dar, M.S.; Aga, M.A.; Ahmad, N.; Manzoor, A.; Qayum, A.; Shah, A.; Mushtaq, S.; Ahmad, Z.; et al. Novel bioactive molecules from Lentzea violacea strain AS 08 using one strain-many compounds (OSMAC) approach. Bioorganic Med. Chem. Lett. 2017, 27, 2579-2582, doi:10.1016/j.bmcl.2017.03.075.

34. Zhang, C.; Seyedsayamdost, M.R. Discovery of a Cryptic Depsipeptide from Streptomyces ghanaensis via MALDI-MS-Guided High-Throughput Elicitor Screening. Angew. Chemie Int. Ed. 2020, 59, 23005-23009, doi:https://doi.org/10.1002/anie.202009611.

35. Genilloud, O. Current challenges in the discovery of novel antibacterials from microbial natural products. Recent Pat. Antiinfect. Drug Discov. 2012, 7, 189-204, doi:10.2174/157489112803521968.

36. Beutler, J.A. Natural Products as a Foundation for Drug Discovery. Curr. Protoc. Pharmacol. 2009, 46, 9.11.1-9.11.21, doi:10.1002/0471141755.ph0911s46.

37. Wohlleben, W.; Mast, Y.; Stegmann, E.; Ziemert, N. Antibiotic drug discovery. Microb. Biotechnol. 2016, 9, 541-548, doi:10.1111/1751-7915.12388.

38. Maansson, M.; Vynne, N.G.; Klitgaard, A.; Nybo, J.L.; Melchiorsen, J.; Nguyen, D.D.; Sanchez, L.M.; Ziemert, N.; Dorrestein, P.C.; Andersen, M.R.; et al. An Integrated Metabolomic and Genomic Mining Workflow To Uncover the Biosynthetic Potential of Bacteria. mSystems 2016, 1, e00028-15, doi:10.1128/mSystems.00028-15.

39. Ong, J.F.M.; Goh, H.C.; Lim, S.C.; Pang, L.M.; Chin, J.S.F.; Tan, K.S.; Liang, Z.-X.; Yang, L.; Glukhov, E.; Gerwick, W.H.; et al. Integrated Genomic and Metabolomic Approach to the Discovery of Potential Anti-Quorum Sensing Natural Products from Microbes Associated with Marine Samples from Singapore. Mar. Drugs 2019, 17, doi:10.3390/md17010072.

40. Tiam, S.K.; Gugger, M.; Demay, J.; Le Manach, S.; Duval, C.; Bernard, C.; Marie, B. Insights into the diversity of secondary metabolites of Planktothrix using a biphasic approach combining global genomics and metabolomics. Toxins (Basel). 2019, doi:10.3390/toxins11090498. 
41. Amiri Moghaddam, J.; Crüsemann, M.; Alanjary, M.; Harms, H.; Dávila-Céspedes, A.; Blom, J.; Poehlein, A.; Ziemert, N.; König, G.M.; Schäberle, T.F. Analysis of the Genome and Metabolome of Marine Myxobacteria Reveals High Potential for Biosynthesis of Novel Specialized Metabolites. Sci. Rep. 2018, doi:10.1038/s41598-018-34954-y.

42. Albarano, L.; Esposito, R.; Ruocco, N.; Costantini, M. Genome mining as new challenge in natural products discovery. Mar. Drugs 2020, 18, 1-17, doi:10.3390/md18040199.

43. Ward, A.C.; Allenby, N.E.E. Genome mining for the search and discovery of bioactive compounds: the Streptomyces paradigm. FEMS Microbiol. Lett. 2018, 365, doi:10.1093/femsle/fny240.

44. Blin, K.; Shaw, S.; Steinke, K.; Villebro, R.; Ziemert, N.; Lee, Y.; Medema, M.H.; Weber, T. antiSMASH 5 . 0 : updates to the secondary metabolite genome mining pipeline. 2019, 47, 81-87, doi:10.1093/nar/gkz310.

45. Wang, M.; Carver, J.J.; Phelan, V. V.; Sanchez, L.M.; Garg, N.; Peng, Y.; Nguyen, D.D.; Watrous, J.; Kapono, C.A.; LuzzattoKnaan, T.; et al. Sharing and community curation of mass spectrometry data with Global Natural Products Social Molecular Networking. Nat. Biotechnol. 2016, 34, 828-837, doi:10.1038/nbt.3597.

46. Yang, J.Y.; Sanchez, L.M.; Rath, C.M.; Liu, X.; Boudreau, P.D.; Bruns, N.; Glukhov, E.; Wodtke, A.; Felicio, R. De; Fenner, A.; et al. Molecular Networking as a Dereplication Strategy. 2013, doi:10.1021/np400413s.

47. Sieber, S.; Grendelmeier, S.M.; Harris, L.A.; Mitchell, D.A.; Gademann, K. Microviridin 1777: A Toxic Chymotrypsin Inhibitor Discovered by a Metabologenomic Approach. J. Nat. Prod. 2020, doi:10.1021/acs.jnatprod.9b00986.

48. Hayakawa, M.; Nonomura, H. Efficacy of artificial humic acid as a selective nutrient in HV agar used for the isolation of soil actinomycetes. J. Ferment. Technol. 1987, 65, 609-616, doi:https://doi.org/10.1016/0385-6380(87)90001-X.

49. Hamada, M.; Lino, T.; Tamura, T.; Iwami, T.; Harayama, S.; Suzuki, K.I. Serinibacter salmoneus gen. nov., sp. nov., an actinobacterium isolated from the intestinal tract of a fish, and emended descriptions of the families Beutenbergiaceae and Bogoriellaceae. Int. J. Syst. Evol. Microbiol. 2009, 59, 2809-2814, doi:10.1099/ijs.0.011106-0.

50. Hamada, M.; Shibata, C.; Nurkanto, A.; Ratnakomala, S.; Lisdiyanti, P.; Tamura, T.; Suzuki, K.I. Serinibacter tropicus sp. nov., an actinobacterium isolated from the rhizosphere of a mangrove, and emended description of the genus Serinibacter. Int. J. Syst. Evol. Microbiol. 2015, doi:10.1099/ijs.0.000068.

51. Hayakawa, M.; Sadakata, T.; Kajiura, T.; Nonomura, H. New methods for the highly selective isolation of Micromonospora and Microbispora from soil. J. Ferment. Bioeng. 1991, 72, 320-326, doi:https://doi.org/10.1016/0922-338X(91)90080-Z.

52. Shirling, E.B.; Gottlieb, D. Methods for characterization of Streptomyces species. Int. J. Syst. Bacteriol. 1966, doi:10.1099/00207713-16-3-313.

53. Grismer, L.L.; Riyanto, A.; Iskandar, D.T.; Mcguire, J.A. A new species of Hemiphyllodactylus Bleeker, 1860 (Squamata: Gekkonidae) from Pulau Enggano, southwestern Sumatra, Indonesia. Zootaxa 2014, 3821, 485-495, doi:10.11646/zootaxa.3821.4.7.

54. Jakl, S. New cetoniine beetle from Enggano and Simeuleu Islands west of Sumatra (Coleoptera: Scarabaeidae: Cetoniinae). Stud. Reports Dist. Museum Prague-East Taxon. Ser. 2008, 4, 103-110.

55. Yoon, S.H.; Ha, S.M.; Kwon, S.; Lim, J.; Kim, Y.; Seo, H.; Chun, J. Introducing EzBioCloud: A taxonomically united database of 16S rRNA gene sequences and whole-genome assemblies. Int. J. Syst. Evol. Microbiol. 2017, doi:10.1099/ijsem.0.001755.

56. Shetty, P.R.; Buddana, S.K.; Tatipamula, V.B.; Naga, Y.V.V.; Ahmad, J. Production of polypeptide antibiotic from Streptomyces parvulus and its antibacterial activity. Brazilian J. Microbiol. 2014, doi:10.1590/S1517-83822014005000022.

57. Handayani, I.; Ratnakomala, S.; Lisdiyanti, P.; Fahrurrozi; Kusharyoto, W.; Alanjary, M.; Ort-Winklbauer, R.; Kulik, A.; Wohlleben, W.; Mast, Y. Complete Genome Sequence of Streptomyces sp. Strain SHP22-7, a New Species Isolated from Mangrove of Enggano Island, Indonesia. Microbiol. Resour. Announc. 2018, doi:10.1128/mra.01317-18.

58. Handayani, I.; Ratnakomala, S.; Lisdiyanti, P.; Fahrurrozi; Alanjary, M.; Wohlleben, W.; Mast, Y. Complete genome sequence of Streptomyces sp. strain BSE7F, a Bali mangrove sediment actinobacterium with antimicrobial activities. Genome Announc. 2018, doi:10.1128/genomeA.00618-18.

59. Krause, J.; Ratnakomala, S.; Lisdiyanti, P.; Ort-Winklbauer, R.; Wohlleben, W.; Mast, Y. Complete Genome Sequence of the 
Putative Phosphonate Producer Streptomyces sp. Strain I6, Isolated from Indonesian Mangrove Sediment. Microbiol. Resour. Announc. 2019, doi:10.1128/mra.01580-18.

60. Tidjani, A.R.; Lorenzi, J.N.; Toussaint, M.; Van Dijk, E.; Naquin, D.; Lespinet, O.; Bontemps, C.; Leblond, P. Massive gene flux drives genome diversity between sympatric Streptomyces conspecifics. MBio 2019, 10, 1-12, doi:10.1128/mBio.01533-19.

61. Subramaniam, G.; Thakur, V.; Saxena, R.K.; Vadlamudi, S.; Purohit, S.; Kumar, V.; Rathore, A.; Chitikineni, A.; Varshney, R.K. Complete genome sequence of sixteen plant growth promoting Streptomyces strains. Sci. Rep. 2020, doi:10.1038/s41598020-67153-9.

62. Ventura, M.; Canchaya, C.; Tauch, A.; Chandra, G.; Fitzgerald, G.F.; Chater, K.F.; van Sinderen, D. Genomics of Actinobacteria: Tracing the Evolutionary History of an Ancient Phylum. Microbiol. Mol. Biol. Rev. 2007, doi:10.1128/mmbr.00005-07.

63. Meier-Kolthoff, J.P.; Göker, M. TYGS is an automated high-throughput platform for state-of-the-art genome-based taxonomy. Nat. Commun. 2019, 10, 2182, doi:10.1038/s41467-019-10210-3.

64. Meier-kolthoff, J.P.; Klenk, H.; Go, M. Taxonomic use of DNA G + C content and DNA - DNA hybridization in the genomic age. 2014, 352-356, doi:10.1099/ijs.0.056994-0.

65. Tindall, B.J.; Rosselló-Móra, R.; Busse, H.J.; Ludwig, W.; Kämpfer, P. Notes on the characterization of prokaryote strains for taxonomic purposes. Int. J. Syst. Evol. Microbiol. 2010, 60, 249-266, doi:10.1099/ijs.0.016949-0.

66. Luo, X.X.; Kai, L.; Wang, Y.; Wan, C.X.; Zhang, L.L. Streptomyces luteus sp. nov., an actinomycete isolated from soil. Int. J. Syst. Evol. Microbiol. 2017, 67, 543-547, doi:10.1099/ijsem.0.001611.

67. Mertz, F.P.; Higgens, C.E. Streptomyces capillispiralis sp. nov. Int. J. Syst. Bacteriol. 1982, 32, 116-124, doi:10.1099/00207713-32$1-116$.

68. Eguchi, T.; Takada, N.; Nakamura, S.; Tanaka, T.; Makino, T.; Oshima, Y. Streptomyces bungoensis sp. nov. Int. J. Syst. Bacteriol. 1993, doi:10.1099/00207713-43-4-794.

69. Huang, X.; Zhou, S.; Huang, D.; Chen, J.; Zhu, W. Streptomyces spongiicola sp. Nov., An actinomycete derived from marine sponge. Int. J. Syst. Evol. Microbiol. 2016, 66, 738-743, doi:10.1099/ijsem.0.000782.

70. Belknap, K.C.; Park, C.J.; Barth, B.M.; Andam, C.P. Genome mining of biosynthetic and chemotherapeutic gene clusters in Streptomyces bacteria. Sci. Rep. 2020, 10, 1-9, doi:10.1038/s41598-020-58904-9.

71. Yamanaka, K.; Oikawa, H.; Ogawa, H.O.; Hosono, K.; Shinmachi, F.; Takano, H.; Sakuda, S.; Beppu, T.; Ueda, K. Desferrioxamine E produced by Streptomyces griseus stimulates growth and development of Streptomyces tanashiensis. Microbiology 2005, doi:10.1099/mic.0.28139-0.

72. Poralla, K.; Muth, G.; Härtner, T. Hopanoids are formed during transition from substrate to aerial hyphae in Streptomyces coelicolor A3(2). FEMS Microbiol. Lett. 2000, doi:10.1016/S0378-1097(00)00259-7.

73. Chater, K.F.; Biró, S.; Lee, K.J.; Palmer, T.; Schrempf, H. The complex extracellular biology of Streptomyces. FEMS Microbiol. Rev. 2010, 34, 171-198, doi:10.1111/j.1574-6976.2009.00206.x.

74. Waksman, S.A.; Lechevalier, H.A.; Schaffner, C.P. Candicidin and other polyenic antifungal antibiotics. Bull. World Health Organ. 1965.

75. Tierrafría, V.H.; Ramos-Aboites, H.E.; Gosset, G.; Barona-Gómez, F. Disruption of the siderophore-binding desE receptor gene in Streptomyces coelicolor A3(2) results in impaired growth in spite of multiple iron-siderophore transport systems. Microb. Biotechnol. 2011, doi:10.1111/j.1751-7915.2010.00240.x.

76. van der Meij, A.; Worsley, S.F.; Hutchings, M.I.; van Wezel, G.P. Chemical ecology of antibiotic production by actinomycetes. FEMS Microbiol. Rev. 2017, 41, 392-416, doi:10.1093/femsre/fux005.

77. Navarro-Muñoz, J.C.; Selem-Mojica, N.; Mullowney, M.W.; Kautsar, S.; Tryon, J.H.; Parkinson, E.I.; De Los Santos, E.L.C.; Yeong, M.; Cruz-Morales, P.; Abubucker, S.; et al. A computational framework for systematic exploration of biosynthetic diversity from large-scale genomic data. bioRxiv 2018, 445270, doi:10.1101/445270.

78.

El-Gebali, S.; Mistry, J.; Bateman, A.; Eddy, S.R.; Luciani, A.; Potter, S.C.; Qureshi, M.; Richardson, L.J.; Salazar, G.A.; Smart, 
A.; et al. The Pfam protein families database in 2019. Nucleic Acids Res. 2019, doi:10.1093/nar/gky995.

79. Yagüe, P.; Lopez-Garcia, M.T.; Rioseras, B.; Sanchez, J.; Manteca, A. New insights on the development of Streptomyces and their relationships with secondary metabolite production. Curr. trends Microbiol. 2012, 8, 65-73.

80. Kieser, T.; Bibb, M.J.; Buttner, M.J.; Chater, K.F.; Hopwood, D.A. Practical Streptomyces genetics; The John Innes Foundation: Norwich, 2000; ISBN 07084062389780708406236.

81. Shannon, P.; Markiel, A.; Ozier, O.; Baliga, N.S.; Wang, J.T.; Ramage, D.; Amin, N.; Schwikowski, B.; Ideker, T. Cytoscape: a software environment for integrated models of biomolecular interaction networks. Genome Res. 2003, 13, 2498-2504, doi:10.1101/gr.1239303.

82. Dührkop, K.; Shen, H.; Meusel, M.; Rousu, J.; Böcker, S. Searching molecular structure databases with tandem mass spectra using CSI:FingerID. Proc. Natl. Acad. Sci. 2015, 112, 12580 LP - 12585, doi:10.1073/pnas.1509788112.

83. Böcker, S.; Dührkop, K. Fragmentation trees reloaded. J. Cheminform. 2016, 8, 5, doi:10.1186/s13321-016-0116-8.

84. van Tamelen, E.E.; Dickie, J.P.; Loomans, M.E.; Dewey, R.S.; Strong, F.M. The Chemistry of Antimycin A. X. Structure of the Antimycins1. J. Am. Chem. Soc. 1961, 83, 1639-1646, doi:10.1021/ja01468a023.

85. Barrow, C.J.; Oleynek, J.J.; Marinelli, V.; Sun, H.H.; Kaplita, P.; Sedlock, D.M.; Gillum, A.M.; Chadwick, C.C.; Cooper, R. Antimycins, inhibitors of ATP-citrate lyase, from a Streptomyces sp. J. Antibiot. (Tokyo). 1997, 50, 729-733, doi:10.7164/antibiotics.50.729.

86. Hosotani, N.; Kumagai, K.; Nakagawa, H.; Shimatani, T.; Saji, I. Antimycins A10 A16, Seven New Antimycin Antibiotics Produced by Streptomyces spp. SPA-10191 and SPA-8893. J. Antibiot. (Tokyo). 2005, 58, 460-467, doi:10.1038/ja.2005.61.

87. Sidebottom, A.M.; Johnson, A.R.; Karty, J.A.; Trader, D.J.; Carlson, E.E. Integrated Metabolomics Approach Facilitates Discovery of an Unpredicted Natural Product Suite from Streptomyces coelicolor M145. ACS Chem. Biol. 2013, 8, 2009-2016, doi:10.1021/cb4002798.

88. Traxler, M.F.; Watrous, J.D.; Alexandrov, T.; Dorrestein, P.C.; Kolter, R. Interspecies Interactions Stimulate Diversification of the Streptomyces coelicolor Secreted Metabolome. MBio 2013, 4, e00459-13, doi:10.1128/mBio.00459-13.

89. Blum, S.; Fielder, H.P.; Groth, I.; Kempter, C.; Stephan, H.; Nicholson, G.; Metzger, J.W.; Jung, G. Biosynthetic capacities of actinomycetes. 4. Echinoserine, a new member of the quinoxaline group, produced by Streptomyces tendae. J. Antibiot. (Tokyo). 1995, 48, 619-625, doi:10.7164/antibiotics.48.619.

90. Cox, G.; Sieron, A.; King, A.M.; De Pascale, G.; Pawlowski, A.C.; Koteva, K.; Wright, G.D. A Common Platform for Antibiotic Dereplication and Adjuvant Discovery. Cell Chem. Biol. 2017, 24, 98-109, doi:10.1016/j.chembiol.2016.11.011.

91. Keller-Schierlein, W.; Mihailovié, M.L.; Prelog, V. Stoffwechselprodukte von Actinomyceten. 15. Mitteilung. über die Konstitution von Echinomycin. Helv. Chim. Acta 1959, 42, 305-322, doi:https://doi.org/10.1002/hlca.19590420127.

92. Yu, Z.; Vodanovic-Jankovic, S.; Ledeboer, N.; Huang, S.-X.; Rajski, S.R.; Kron, M.; Shen, B. Tirandamycins from Streptomyces sp. 17944 inhibiting the parasite Brugia malayi asparagine tRNA synthetase. Org. Lett. 2011, 13, 2034-2037, doi:10.1021/ol200420u.

93. Carlson, J.C.; Li, S.; Burr, D.A.; Sherman, D.H. Isolation and Characterization of Tirandamycins from a Marine-Derived Streptomyces sp. J. Nat. Prod. 2009, 72, 2076-2079, doi:10.1021/np9005597.

94. Kluepfel, D.; Baker, H.A.; Piattoni, G.; Sehgal, S.N.; Sidorowicz, A.; Singh, K.; Vézina, C. Naphthyridinomycin, a new broadspectrum antibiotic. J. Antibiot. (Tokyo). 1975, 28, 497-502, doi:10.7164/antibiotics.28.497.

95. Cang, S.; Ohta, S.; Chiba, H.; Johdo, O.; Nomura, H.; Nagamatsu, Y.; Yoshimoto, A. New naphthyridinomycin-type antibiotics, aclidinomycins A and B, from Streptomyces halstedi. J. Antibiot. (Tokyo). 2001, 54, 304-307, doi:10.7164/antibiotics.54.304.

96. Bernan, V.S.; Montenegro, D.A.; Korshalla, J.D.; Maiese, W.M.; Steinberg, D.A.; Greenstein, M. Bioxalomycins, new antibiotics produced by the marine Streptomyces sp. LL-31F508: taxonomy and fermentation. J. Antibiot. (Tokyo). 1994, 47, 1417-1424, doi:10.7164/antibiotics.47.1417.

97. Banskota, A.H.; McAlpine, J.B.; Sørensen, D.; Ibrahim, A.; Aouidate, M.; Piraee, M.; Alarco, A.M.; Farnet, C.M.; Zazopoulos, 
E. Genomic analyses lead to novel secondary metabolites: Part 3 ECO-0501, a novel antibacterial of a new class. J. Antibiot. (Tokyo). 2006, 59, 533-542, doi:10.1038/ja.2006.74.

98. Stevens, C.L.; Nagarajan, K.; Haskell, T.H. The Structure of Amicetin. J. Org. Chem. 1962, 27, 2991-3005, doi:10.1021/jo01056a006.

99. Haneda, K.; Shinose, M.; Seino, A.; Tabata, N.; Tomoda, H.; Iwai, Y.; Omura, S. Cytosaminomycins, new anticoccidial agents produced by Streptomyces sp. KO-8119. I. Taxonomy, production, isolation and physico-chemical and biological properties. J. Antibiot. (Tokyo). 1994, 47, 774-781, doi:10.7164/antibiotics.47.774.

100. Bu, Y.; Yamazaki, H.; Ukai, K.; Namikoshi, M. Anti-Mycobacterial Nucleoside Antibiotics from a Marine-Derived Streptomyces sp. TPU1236A. 2014, 6102-6112, doi:10.3390/md12126102.

101. Zhou, S.; Xiao, K.; Huang, D.; Wu, W.; Xu, Y.; Xia, W. Complete genome sequence of Streptomyces spongiicola HNM0071T , a marine sponge-associated actinomycete producing staurosporine and echinomycin Marine Genomics Complete genome sequence of Streptomyces spongiicola HNM0071 T, a marine sponge-associated act. Mar. Genomics 2018, 0-1, doi:10.1016/j.margen.2018.08.002.

102. Ito, T.; Masubuchi, M. Dereplication of microbial extracts and related analytical technologies. J. Antibiot. (Tokyo). 2014, doi:10.1038/ja.2014.12.

103. Gaudêncio, S.P.; Pereira, F. Dereplication: Racing to speed up the natural products discovery process. Nat. Prod. Rep. 2015, 32, 779-810, doi:10.1039/c4np00134f.

104. Carrano, L.; Marinelli, F. The relevance of chemical dereplication in microbial natural product screening. J. Appl. Bioanal. 2015, 1, 55-67, doi:10.17145/jab.15.010.

105. Chiani, M.; Akbarzadeh, A.; Farhangi, A.; Mazinani, M.; Saffari, Z.; Emadzadeh, K.; Mehrabi, M.R. Optimization of culture medium to increase the production of desferrioxamine B (Desferal) in Streptomyces pilosus. Pakistan J. Biol. Sci. 2010, doi:10.3923/pjbs.2010.546.550.

106. Chiani, M.; Akbarzadeh, A.; Farhangi, A.; Mehrabi, M.R. Production of Desferoxamine B (Desferal) using Corn Steep Liquor in Streptomyces pilosus. Pakistan J. Biol. Sci. 2010, doi:10.3923/pjbs.2010.1151.1155.

107. Kase, H.; Fujita, H.; Nakamura, J.; Hashizume, K.; Goto, J.; Kubo, K.; Shuto, K. MY336-A, a novel $\beta$-adrenergic receptor antagonist produced by Streptomyces gabonae. J. Antibiot. (Tokyo). 1986, doi:10.7164/antibiotics.39.354.

108. Sambrook, J.; Fritsch, E.F.; Maniatis, T. Molecular Cloning: A Labortaroy Manual; 1989; ISBN 0879695773.

109. Garg, N.; Kapono, C.A.; Lim, Y.W.; Koyama, N.; Vermeij, M.J.A.; Conrad, D.; Rohwer, F.; Dorrestein, P.C. Mass spectral similarity for untargeted metabolomics data analysis of complex mixtures. Int. J. Mass Spectrom. 2015, doi:10.1016/j.ijms.2014.06.005.

110. Zani, C.L.; Carroll, A.R. Database for Rapid Dereplication of Known Natural Products Using Data from MS and Fast NMR Experiments. J. Nat. Prod. 2017, doi:10.1021/acs.jnatprod.6b01093. 